\title{
Orbitofrontal Cortex Encodes Preference for Alcohol
}

\author{
John S. Hernandez ${ }^{1}$ and David E. Moorman ${ }^{1,2}$
}

https://doi.org/10.1523/ENEURO.0402-19.2020

${ }^{1}$ Neuroscience and Behavior Graduate Program, University of Massachusetts Amherst, Amherst, MA 01003 and

${ }^{2}$ Department of Psychological and Brain Sciences, University of Massachusetts Amherst, Amherst, MA 01003

\begin{abstract}
Orbitofrontal cortex (OFC) plays a key role in representation and regulation of reward value, preference, and seeking. OFC function is disrupted in drug use and dependence, but its specific role in alcohol use disorders has not been thoroughly studied. In alcohol-dependent humans OFC activity is increased by alcohol cue presentation. Ethanol (EtOH) also alters OFC neuron excitability in vitro, and OFC manipulation influences EtOH seeking and drinking in rodents. To understand the relationship between OFC function and individual alcohol use, we recorded OFC neuron activity in rats during EtOH self-administration, characterizing the neural correlates of individual preference for alcohol. After one month of intermittent access to $20 \% \mathrm{EtOH}$, male LongEvans rats were trained to self-administer $20 \% \mathrm{EtOH}, 10 \% \mathrm{EtOH}$, and $15 \%$ sucrose. OFC neuronal activity was recorded and associated with task performance and $\mathrm{EtOH}$ preference. Rats segregated into high and low $\mathrm{EtOH}$ drinkers based on homecage consumption and operant seeking of $20 \% \mathrm{EtOH}$. Motivation for $10 \% \mathrm{EtOH}$ and sucrose was equally high in both groups. OFC neuronal activity was robustly increased or decreased during sucrose and EtOH seeking and consumption, and strength of changes in OFC activity was directly associated with individual preference for $20 \% \mathrm{EtOH}$. EtOH-associated OFC activity was more similar to sucroseassociated activity in high versus low EtOH drinkers. The results show that OFC neurons are activated during alcohol seeking based on individual preference, supporting this brain region as a potential substrate for alcohol motivation that may be dysregulated in alcohol misuse.
\end{abstract}

Key words: alcohol use disorder; dependence; electrophysiology; instrumental; orbital cortex; prefrontal cortex

\section{Significance Statement}

Understanding how alcohol preference manifests in the brain is important for understanding use and misuse. We trained rats to self-administer alcohol and sucrose, as a positive preference control. During self-administration, we recorded the activity of neurons in the orbitofrontal cortex (OFC), an area previously associated with reward motivation and drug use. OFC neuronal activity was aligned with behavioral alcohol preference, both at a population level and on an individual basis. OFC activity of high alcohol-preferring rats during alcohol seeking and consumption was similar to that seen during sucrose-associated behaviors. These data provide evidence that the OFC is a key region underlying individual alcohol preference and suggests further scrutiny of OFC in the context of alcohol use disorder.

\section{Introduction}

The orbitofrontal cortex (OFC) regulates reward seeking and cognitive strategies associated with optimizing outcomes (Dalley et al., 2004; Kringelbach and Rolls, 2004;

\footnotetext{
Received October 3, 2019; accepted February 12, 2020; First published July 13, 2020.

The authors declare no competing financial interests.
}

O’Doherty, 2007; Mainen and Kepecs, 2009; Schoenbaum et al., 2009; Balleine et al., 2011; Padoa-Schioppa, 2011; Wallis, 2011; Walton et al., 2011; McDannald et al., 2014a; Rudebeck and Murray, 2014; Izquierdo, 2017). OFC is

Author contributions: J.S.H. and D.E.M. designed research; J.S.H. performed research; J.S.H. and D.E.M. analyzed data; J.S.H. and D.E.M. wrote the paper. 
activated during craving and seeking of drugs of abuse and in response to drug-associated cues (Garavan et al., 2000; Risinger et al., 2005; Baeg et al., 2009; Guillem et al., 2010, 2018; Guillem and Ahmed, 2018a). OFC hypoactivity is associated with impulsivity and drug use disorders (Whelan et al., 2012). Based on these and other results, OFC disruption has been hypothesized to be a major factor underlying drug addiction (London et al., 2000; Porrino and Lyons, 2000; Volkow and Fowler, 2000; Dom et al., 2005; Everitt et al., 2007; Winstanley, 2007; Schoenbaum and Shaham, 2008; Lucantonio et al., 2014; Fettes et al., 2017). However, only a subset of addiction-related studies has investigated the role of OFC in alcohol use.

There is some evidence for a role for OFC in alcohol motivation and dependence (Moorman, 2018). OFC activation in humans has been associated with alcohol-related craving (Myrick et al., 2004, 2008; Lukas et al., 2013; Schacht et al., 2013a,b, 2014). Connectivity between OFC and striatum is altered in abstinent alcoholics (Volkow et al., 2007). Chronic alcohol (ethanol, EtOH) results in cognitive deficits associated with OFC dysfunction (Lejuez et al., 2010; Badanich et al., 2011). EtOH consumption and reinstatement increases Fos and $\Delta$ FosB expression in rodent OFC (Li et al., 2010; Jupp et al., 2011). Acute EtOH in vitro inhibits OFC neuron excitability and synaptic function (Badanich et al., 2013b). In mice withdrawn from chronic EtOH vapor, OFC neurons display increases in spine density and basal excitability and a diminished inhibitory response to acute $\mathrm{EtOH}$ (McGuier et al., 2015; Nimitvilai et al., 2016). OFC lesions or DREADD inhibition increased alcohol drinking in rats and $\mathrm{EtOH}$ vapor-treated mice (den Hartog et al., 2016; Ray et al., 2018), and inactivation decreased context-induced reinstatement in rats (Bianchi et al., 2018).

Missing from these studies is an analysis of neural dynamics associated with alcohol seeking, and how these dynamics may vary across individuals. Alcohol motivation varies among human and animal subjects, and individuals exhibiting greater euphoric or stimulating effects of alcohol may be at greater risk for misuse and dependence (King et al., 2011; Sharko et al., 2013; Momeni and Roman, 2014; Spoelder et al., 2015; Moorman et al., 2016, 2017; Juarez et al., 2017). Given the strong association between OFC neuronal function and individual preferences for natural rewards, cocaine, and heroin (Tremblay and Schultz, 1999; Padoa-Schioppa and Assad, 2006; Schultz, 2010; Guillem and Ahmed, 2018b; Guillem et al.,

This work was supported by National Institutes of Health (NIH) Research Grants AA024571, AA025481, and DA041674; a National Alliance for Research on Schizophrenia and Depression Young Investigator Grant from the Brain \& Behavior Research Foundation (D.E.M.), and the NIH Research Grant GM099649 (to J.S.H.).

Acknowledgements: We thank Ifeyinwa Arinze, Rachel Siegal, and Kathy Tran for research and technical support.

Correspondence should be addressed to David E. Moorman at moorman@ umass.edu.

https://doi.org/10.1523/ENEURO.0402-19.2020

Copyright (C) 2020 Hernandez and Moorman

This is an open-access article distributed under the terms of the Creative Commons Attribution 4.0 International license, which permits unrestricted use, distribution and reproduction in any medium provided that the original work is properly attributed.
2018), we predicted that differential OFC activity may reflect individual alcohol preferences. We characterized individual preference for EtOH in outbred Long-Evans rats and identified OFC correlates of this preference by recording neuronal activity during operant $\mathrm{EtOH}$ or sucrose seeking. Our results indicate that OFC neurons are strongly, but differentially, activated during EtOH and sucrose seeking, and that degree of activation is associated with individual $\mathrm{EtOH}$ preference.

\section{Materials and Methods}

Male Long-Evans rats $(n=24 ; \sim 200-300 \mathrm{~g}$ on arrival; Charles River Laboratories) were kept in temperaturecontrolled and humidity-controlled conditions under reversed light/dark cycle (7 A.M. off to 7 P.M. on). Water was available ad libitum, and rats were restricted to $25 \mathrm{~g}$ of rat chow given after daily operant sessions once they reached $300 \mathrm{~g}$. All animal procedures were approved by the Institutional Animal Care and Use Committee at the University of Massachusetts Amherst and were conducted in compliance with the National Institutes of Health Guide for the Care and Use of Animals.

\section{Experimental design}

Experimental design is shown in Figure $1 A$. Animals were trained to drink 20\% EtOH (Fisher Scientific) for one month in their home cages using the intermittent access to EtOH paradigm (Wise, 1975; Simms et al., 2008; Moorman and Aston-Jones, 2009; Carnicella et al., 2014; Moorman et al., 2016, 2017), with ad libitum access to food and water. Rats were then trained to perform operant $\mathrm{EtOH}$ and sucrose seeking on an fixed ratio 1 (FR1) schedule (Fig. 1C). Behavioral testing was conducted in operant chambers (Med Associates) equipped with a house-light, nosepoke, and reward delivery port containing a spigot to deliver three rewards (15\% sucrose, $10 \% \mathrm{EtOH}, 20 \%$ EtOH) separately. Nosepokes, reward port entries, and licks were detected with infrared beam breaks, thereby reducing electrical noise for electrophysiological recording. Fluids were consumed at the spigot only (there was no collection well). Non-consumed sucrose or alcohol drained away from the reward delivery port to prevent fluid mixing. Rats were initially trained on FR1 nosepoke responses for a sucrose cue $(5-\mathrm{kHz}$ tone, duration $400-600 \mathrm{~ms})$ and $0.1-\mathrm{ml}$ sucrose delivery through the spigot. After rats reached a criterion of $85 \%$ successful trials (retrieving sucrose within 500-ms postcue onset), rats were prepared for surgical implantation of recording arrays. Homecage $\mathrm{EtOH}$ access was used to train rats to drink $\mathrm{EtOH}$ as well as to characterize individual $\mathrm{EtOH}$ preference in the absence of any additional demands that might be present in an operant context.

After recovery, rats were retrained on the nosepokecue-sucrose task for $2 \mathrm{~d}$. We then recorded OFC neuron activity while rats performed nosepoke-cue-outcome tasks, where cue-outcome pairings were $5-\mathrm{kHz}$ tone$15 \%$ sucrose, $1-\mathrm{kHz}$ tone- $20 \% \mathrm{EtOH}$, or $10-\mathrm{kHz}$ tone$10 \% \mathrm{EtOH}$. Recording sessions consisted of either blocked trials (where all trials per session/day were one cue-outcome pairing) or interleaved trials (where sucrose and $20 \% \mathrm{EtOH}$ trials were pseudorandomly interleaved). 
A

\begin{tabular}{|cccccc|}
\hline $\begin{array}{l}\text { Intermittent } \\
\text { Access } \\
20 \% \text { EtOH } \\
1 \text { month }\end{array} \rightarrow \begin{array}{c}\text { Operant } \\
\text { training } \\
\text { to criteria }\end{array} \rightarrow \begin{array}{c}\text { Surgeryl } \\
\text { Recovery } \\
>1 \text { week }\end{array} \rightarrow \begin{array}{c}\text { Operant } \\
\text { retraining } \\
\text { (sucrose/EtOH) }\end{array}$ & $\begin{array}{c}\text { Neuronal recording across days: } \\
\text { 1) Sucrose } \\
2) 10 \% \mathrm{EtOH} \\
3) 20 \% \mathrm{EtOH}\end{array}$ \\
\end{tabular}

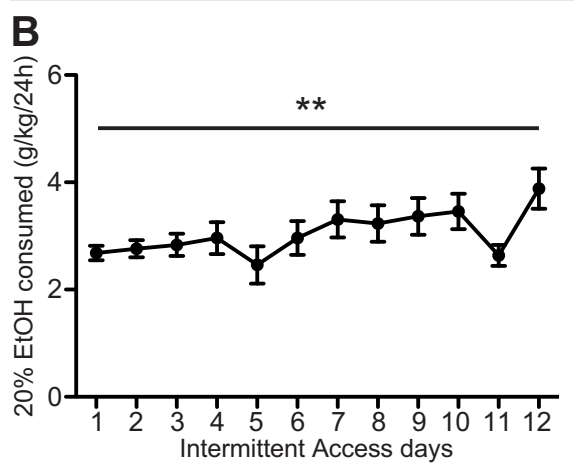

C
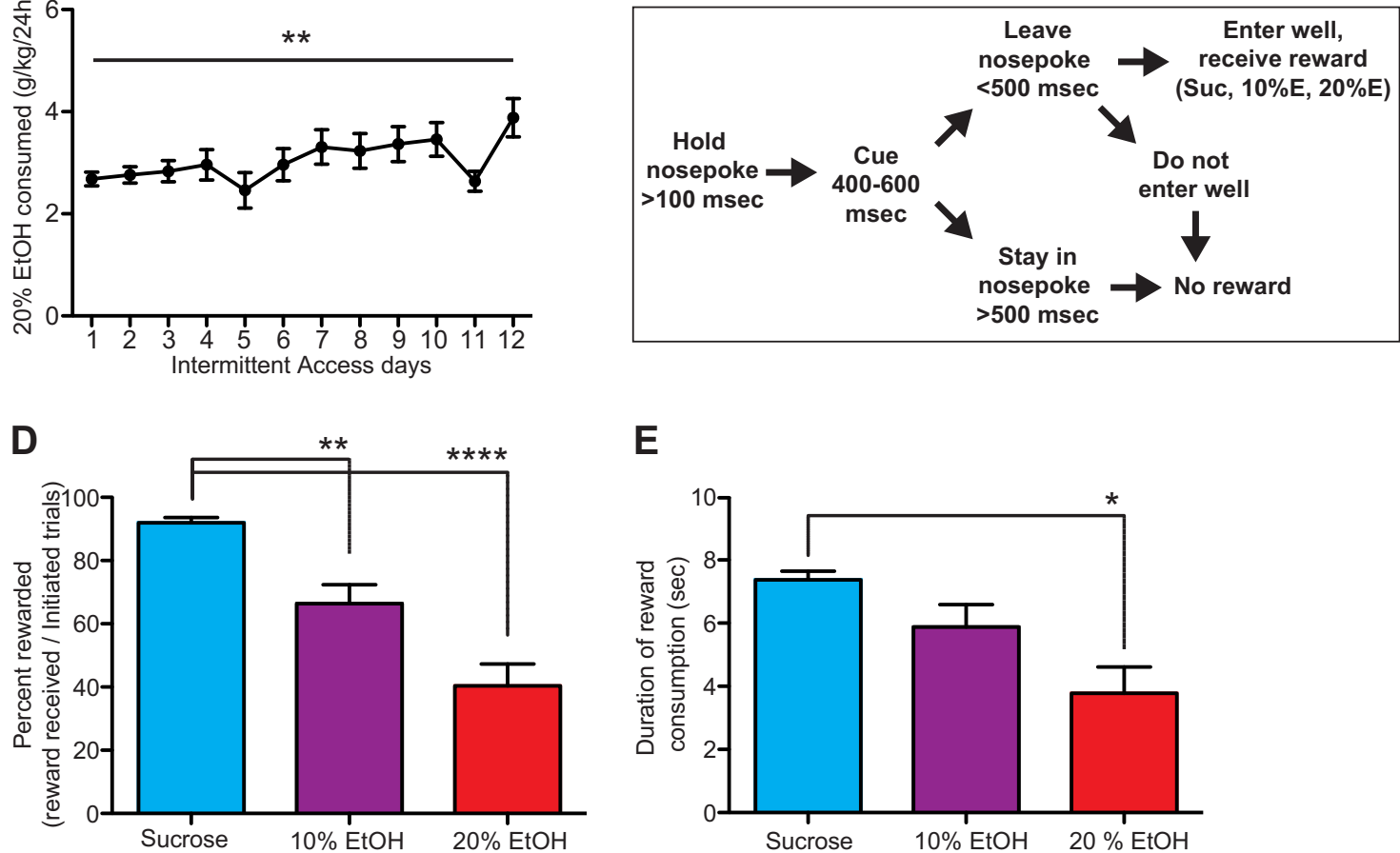

$\mathbf{E}$

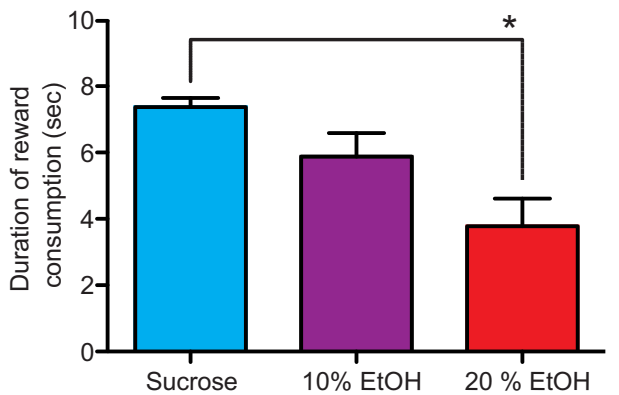

Figure 1. $\boldsymbol{A}$, Experimental timeline. $\boldsymbol{B}$, Rats received 12-d homecage intermittent access to EtOH. Consumption escalated significantly over days. $\boldsymbol{C}$, Operant task diagram. Rats nosepoked to receive cues predicting sucrose or EtOH. Outcomes were consumed by licking a spigot in a reward port below the nosepoke. $\boldsymbol{D}$, Rats acquired significantly more sucrose (blue) than $10 \% \mathrm{EtOH}$ (purple) or $20 \% \mathrm{EtOH}$ (red) rewards. $\boldsymbol{E}$, Rats consumed significantly more sucrose than $20 \% \mathrm{EtOH}$ based on duration of reward consumption; $* p<0.05, * * p<0.01, * * * * p<0.0001$.

Because it is difficult to reliably claim stable recording of the same neuron across multiple days using microwire arrays, we included the interleaved sessions so that we could compare the activity of OFC neurons during both $\mathrm{EtOH}$ and sucrose conditions. All trials were self-initiated, and animals were free to consume or not consume rewards after trial initiation. All sessions lasted $1 \mathrm{~h}$. During blocked sessions, only one cue-outcome set of trials was presented each day, mitigating concerns that previous blocks may have influenced expectations on the current recording session. For each cue-outcome pairing, OFC activity was recorded two times (once per day for $2 \mathrm{~d}$ ). Activity from the session with the best quality recording (signal-to-noise, numbers of neurons) was included in analysis. All rats received at least one (typically three or more) days of $10 \%$ or $20 \%$ EtOH self-administration before OFC recording, mitigating concerns that OFC activity on $\mathrm{EtOH}$ self-administration days reflected a deviation from expected sucrose reward.

\section{Surgery}

Surgical methods were similar to our previous work (Moorman and Aston-Jones, 2014, 2015). Rats were given $100 \mathrm{mg} / \mathrm{l}$ minocycline $\mathrm{HCl}$ (Henry Schein Medical) ad libitum $2 \mathrm{~d}$ before and $5 \mathrm{~d}$ after array implantation. Meloxicam (Metacam; Henry Schein Medical) was administered $1.36 \mathrm{mg} / \mathrm{kg}$ (subcutaneously). Under isoflurane anesthesia (1.5-2.5\%), custom-made, static arrays of 32 recording electrodes $(50-\mu \mathrm{m}$ nichrome wires, $200-\mu \mathrm{m}$ spacing center-to-center) were implanted unilaterally in OFC. Arrays spanned from medial OFC (mOFC: A/P 3.6$4.6 \mathrm{~mm}, \mathrm{M} / \mathrm{L} 0.7 \mathrm{~mm}, \mathrm{D} / \mathrm{V}-5.0$ to $-5.2 \mathrm{~mm}$ from bregma) to lateral OFC (IOFC: A/P 3.6-4.6 mm, M/L 2.6-3.0 mm, $\mathrm{D} / \mathrm{V}-5.0$ to $-5.2 \mathrm{~mm}$ from bregma).

\section{Electrophysiological recordings}

Electrophysiological recordings were performed using a Digital Lynx system (Neuralynx). OFC neurons were recorded on each blocked and interleaved session for $2 \mathrm{~d}$. Wideband signals were filtered $300-3000 \mathrm{~Hz}$ and thresholded to identify well isolated action potentials ( $\geq 4 \mathrm{SD}$ from mean of peak height of noise band), which were manually sorted in Offline Sorter (Plexon). Well-isolated units that fired throughout each recording session were included in analyses. 


\section{Histology}

After the final recording, rats were anesthetized with $1.5-2.5 \%$ isoflurane and constant current $(25 \mu \mathrm{A})$ was delivered to each recording wire for $15 \mathrm{~s}$ to produce lesions to mark the tips of recording electrodes. One day later, rats were perfused with $0.9 \% \mathrm{NaCl}$ solution followed by $4 \%$ paraformaldehyde. Brains were postfixed overnight with $4 \%$ paraformaldehyde and cryoprotected in a $20 \%$ sucrose/ $0.1 \%$ sodium azide solution. Forty-micrometer sections were stained with neutral red to confirm electrode placement.

\section{Data analysis}

Rats were identified as high drinkers (HD) or low drinkers (LD) if mean EtOH consumption on the final $3 \mathrm{~d}$ of homecage intermittent access was greater or less than $3.5 \mathrm{~g} / \mathrm{kg} /$ 24 h, respectively (George et al., 2012; Momeni and Roman, 2014; Spoelder et al., 2015). Operant behaviors analyzed included total number of rewards received, percent rewarded trials, average duration of reward consumption, and latency to acquire reward. Behavioral and neurophysiological data were analyzed using standard parametric or nonparametric tests depending on normality, using Prism (GraphPad) or custom analyses in MATLAB (MathWorks).

Neuronal activity was grouped in 50 -ms bins and aligned to task events. Spike density functions (SDFs) were generated by Gaussian smoothing. Population activity plots were made by $z$ score normalizing event-related neuronal activity against baseline activity preceding trial initiation. OFC response strength was calculated with the index:

\section{(Behavioral epoch activity - baseline activity)

(Behavioral epoch activity + baseline activity)

where activity was number of spikes during a given behavioral epoch or a baseline epoch of equal duration sampled, on a trial-by-trial basis, from the pre-trial-initiation intertrial interval. Three main test epochs were studied along with trial-matched baseline epochs: postcue/preseeking (cue onset to cue $+100 \mathrm{~ms}$ ), reward seeking (400-ms prereward receipt to reward receipt, measured as first rewarded lick), and reward consumption (first rewarded lick to last rewarded lick). Wilcoxon signed-rank tests were used to measure significant shifts from zero in distribution plots for all indices (Roesch et al., 2012; Takahashi et al., 2013). Each epoch was aligned to an event that, because of the selfpaced nature of the task, was variable from trial to trial. Although rats performed the task consistently across trials, the inherent variability in the trial initiation, nosepoke-exit, and reward consumption, permitted analyses focused specifically on those events. All analyses were considered significant at $\alpha=0.05$.

\section{Results}

Rats engaged in EtOH and sucrose seeking and consumption, preferring sucrose more than EtOH, and $10 \%$ EtOH more than $20 \%$ EtOH

Across all rats $20 \%$ EtOH consumption escalated slightly but significantly during homecage intermittent access $\left(H_{(11)}=25.58, p=0.008\right.$, Kruskal-Wallis; Fig. $\left.1 B\right)$. During operant testing, rats nosepoked to receive a tone cue predicting one of three outcomes $(20 \% \mathrm{EtOH}, 10 \%$ $\mathrm{EtOH}$, or $15 \%$ sucrose; Fig. 1C). Following cue presentation, rats withdrew from the nosepoke and received reward from a spigot directly below the nosepoke. Of the 24 rats tested in homecage intermittent access, 16 rats were used for neurophysiological recording during operant sucrose and $20 \%$ EtOH seeking sessions, and 12/ 16 rats were also used for recording during $10 \% \mathrm{EtOH}$ sessions.

Reward motivation, measured as percent rewarded trials (number of rewarded trials divided by number of initiated trials), was significantly influenced by reward type $\left(H_{(2)}=26.54, p<0.0001\right.$; Fig. $\left.1 D\right)$. Rats received significantly more sucrose than $20 \% \mathrm{EtOH}$ rewards $[p<0.0001$, Dunn's multiple comparisons test (MCT)] and 10\% EtOH rewards $(p=0.007)$. Rats also received fewer $20 \% \mathrm{EtOH}$ than $10 \% \mathrm{EtOH}$ rewards, although this difference was not significant. We also quantified consumption via licking duration, measured from first lick during reward delivery to the final lick of that trial, for each outcome as a measure of preference. As with reward acquisition, reward consumption (Fig. 1E) was significantly different across conditions $\left(H_{(2)}=9.16, p=0.010\right)$ and was greater for sucrose than $20 \%$ and $10 \% \mathrm{EtOH}$, with the difference between sucrose and $20 \%$ EtOH being significant $(p=0.008$, Dunn's MCT).

We also measured response latencies to verify that our analysis epochs captured non-overlapping neural correlates of behavior. Median latencies from cue onset to nosepoke exit were $110 \mathrm{~ms}$ (sucrose), $210 \mathrm{~ms}$ (10\% $\mathrm{EtOH})$, and $170 \mathrm{~ms}(20 \% \mathrm{EtOH})$, so our "cue" analysis epoch (cue onset time to cue $+100 \mathrm{~ms}$ ) was focused on the cue-evoked decision and initiation of the nosepoke exit response. Median latencies from nosepoke exit to first reward lick were $890 \mathrm{~ms}$ (sucrose), $960 \mathrm{~ms}$ (10\% $\mathrm{EtOH})$, and $1355 \mathrm{~ms}$ (20\% EtOH). Thus, the "seeking" analysis epoch (400 ms before first rewarded lick to first rewarded lick) was focused exclusively on reward-seeking behaviors and did not overlap with nosepoke exit or cue presentation.

\section{OFC neuronal activity was strongly but differentially altered during sucrose and EtOH seeking and consumption}

Based on histologic characterization of postrecording lesion sites, neurons were recorded from OFC but spanned the extent of mOFC, ventral OFC (vOFC), and IOFC (Fig. 2A). OFC neuronal activity was analyzed during three epochs: cue presentation, reward seeking, and reward consumption (Materials and Methods). During sucrose sessions, OFC neurons were suppressed during cue presentation, activated during reward seeking, and again suppressed during reward consumption (Fig. 2B-D, blue), consistent with our previous report (Moorman and Aston-Jones, 2014), although there were examples of individual neurons exhibiting different profiles (Figs. 2D, 3). During $10 \%$ EtOH trials, OFC neurons exhibited a similar pattern to that seen during sucrose seeking and 
A

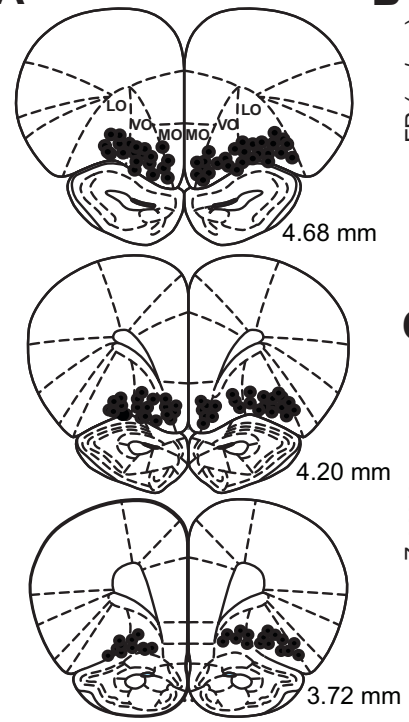

B

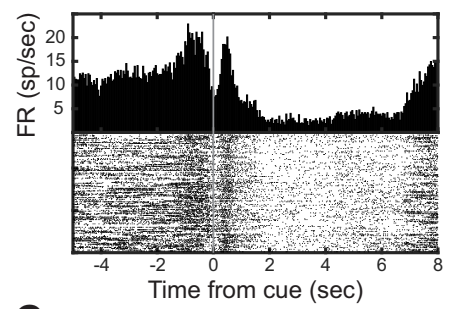

C

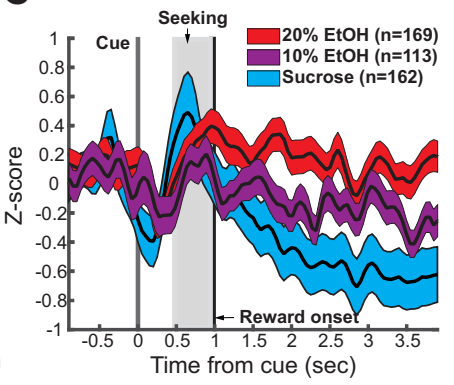

D

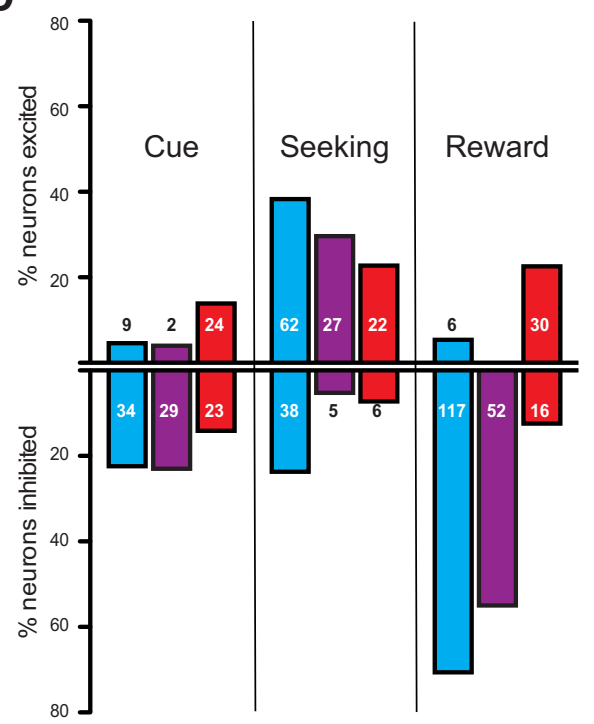

Figure 2. $\boldsymbol{A}$, Recording sites in the OFC (black circles) based on lesions made postrecording. $\boldsymbol{B}$, Example activity from OFC neuron recorded during a sucrose session. Rasters (bottom) and 50-ms bin histogram (top) show the prominent inhibition during cue presentation followed by excitation during reward seeking and inhibition during reward consumption. $\mathbf{C}$, Z-scored average OFC activity with standard error confidence intervals (Cls) across all neurons aligned on cue presentation in sucrose (blue $\mathrm{Cl}$ ), $10 \% \mathrm{EtOH}$ (purple $\mathrm{Cl}$ ), and $20 \% \mathrm{EtOH}$ (red Cl) sessions. $\boldsymbol{D}$, Numbers of neurons significantly excited or inhibited during each epoch in sucrose (blue), $10 \% \mathrm{EtOH}$ (purple), and 20\% EtOH (red) sessions.

consumption (Figs. $2 C, D$, purple, 3 ), but with slightly reduced proportions of responses and a stronger bias toward excitation during seeking. During $20 \% \mathrm{EtOH}$ sessions, OFC neuronal activity was significantly increased and decreased, but the proportions of excitation versus inhibition were strikingly different during cue presentation and reward consumption (Figs. $2 C, D$, red, $3)$. This was particularly salient during consumption in which the strong bias toward inhibition seen in sucrose and $10 \% \mathrm{EtOH}$ was reversed and more neurons exhibited excitation. There were no significant differences in baseline activity, measured during the intertrial interval, across sessions (see below).

\section{OFC neuronal response properties were consistent with the population, but overall heterogeneous}

The differences in proportions of significantly upregulated/downregulated neurons shown in Figure 2 were consistent with distributions of response indices of single neurons shown in Figure 3. During the cue presentation epoch (Fig. 3, left column), neuronal activity was significantly suppressed in both sucrose (significant neurons (sig): $z=-4.25, p<0.0001$; all neurons (all): $z=-5.00$, $p=0.0008$; Wilcoxon) and $10 \% \mathrm{EtOH}$ (sig: $z=-7.12$, $p=0.0004$; all: $z=-3.94, p<0.0001)$ trials, whereas activity was not significantly biased in $20 \% \mathrm{EtOH}$ trials (sig: $z=-0.46, p=0.8$; all: $z=-0.29, p=0.7)$. During reward seeking (Fig. 3, center column), activity was biased toward excitation in sucrose (sig: $z=4.77, p<0.0001$; all: $z=3.16, p=0.008$ ), $10 \%$ EtOH (sig: $z=3.59, p=0.0004$; all: $z=5.46, p<0.0001$ ) and $20 \% \mathrm{EtOH}$ (sig: $z=1.55, p=$ 0.1 ; all: $z=4.29, p=0.006$ ) trials. During reward consumption (Fig. 3, right column), activity was significantly reduced during sucrose (sig: $z=-8.94, p<0.0001$; all: $z$ $=-7.56, p<0.0001$; Wilcoxon) and $10 \%$ EtOH consumption (sig: $\mathrm{z}=-7.32, \quad p<0.0001$; all: $\mathrm{z}=-6.27$. $p<0.0001$ ). In contrast, during $20 \% \mathrm{EtOH}$ consumption, few neurons were significantly suppressed, and more neurons actually exhibited increased activation. This excitation bias was significant for neurons with significant changes in firing rates $(z=3.06, p=0.0002)$ but not across the whole population $(z=0.87, p=0.4)$. Differences between distributions were significant (cue: $F_{(2,433)}=7.7629$, $p=0.022$; seeking: $F_{(2,381)}=12.24, p=0.027$; consumption: $F_{(2,388)}=49.229, p<0.0001$; Kruskal-Wallis). These differences were driven by significant differences in distribution of responses to sucrose versus 20\% EtOH (cue: $p=0.0187$, seeking: $p=0.023$, consumption: $p<0.0001$ ) and, during reward consumption, $10 \% \mathrm{EtOH}$ versus $20 \% \mathrm{EtOH}$ (cue: $p=0.3337$, seeking: $p=0.17$, consumption: $p<0.0001$ ), but not sucrose versus $10 \% \mathrm{EtOH}$ (cue: $p=1$, seeking: $p=1$, consumption: $p=0.8931$ ). When isolating significantly modulated neurons, distributions were significantly different (cue: $F_{(2,121)}=8.759, p=0.0125$; seeking: $F_{(2,179)}=11.06$, $p=0.004$; consumption: $F_{(2,221)}=63.58, \quad p<0.0001$; Kruskal-Wallis). These significant differences were driven by differences in distribution of responses to sucrose and $20 \%$ EtOH (cue: $p=0.032$, seeking: $p=0.0366$, consumption: $p<0.0001$ ) as well as $10 \% \mathrm{EtOH}$ and $20 \% \mathrm{EtOH}$ (cue: $p=0.042$, seeking: $p=0.049$, consumption: $p<0.0001$ ). Thus, both in populations of neurons with significantly different firing rates, and across the population as a whole, OFC neurons exhibited differential outcome classification, based on proportions of excitatory and inhibitory responses, at different task stages.

Although Figures 2, 3 provide a summary of the overall output of OFC combined across neurons, Figure 3 also 
Cue
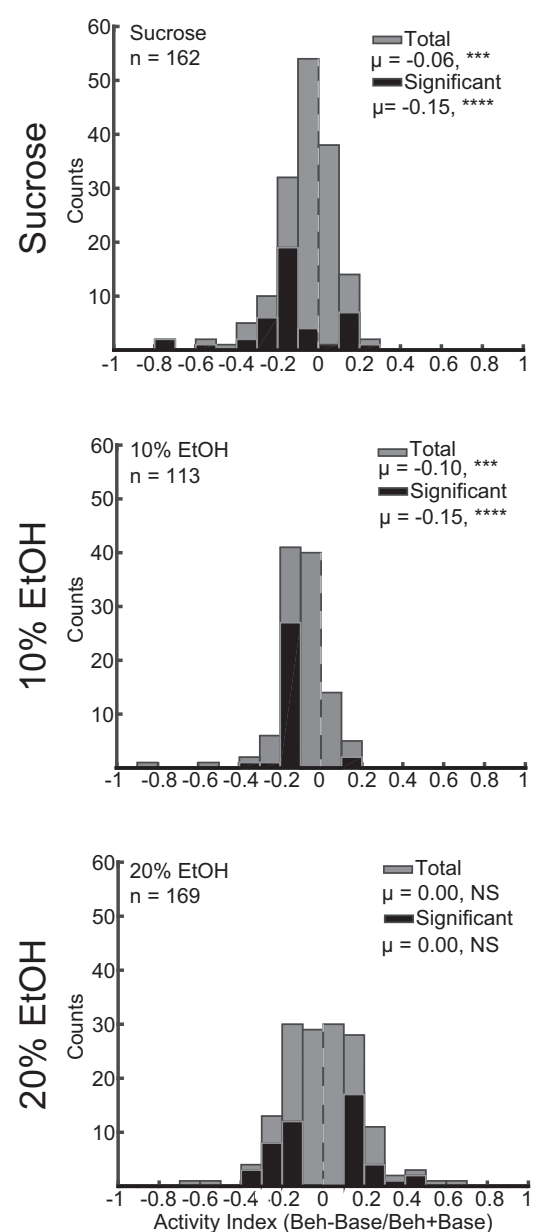

Seeking
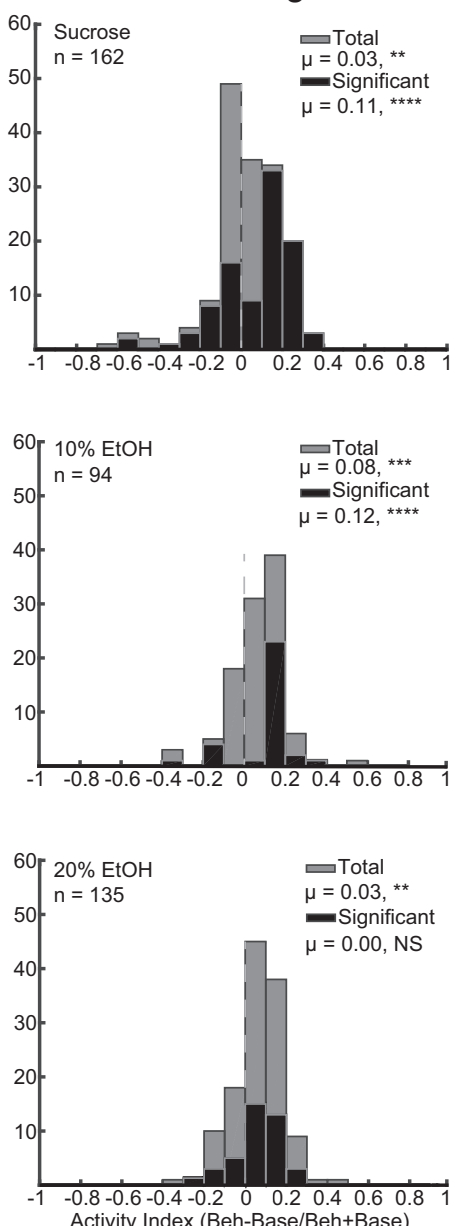

Reward
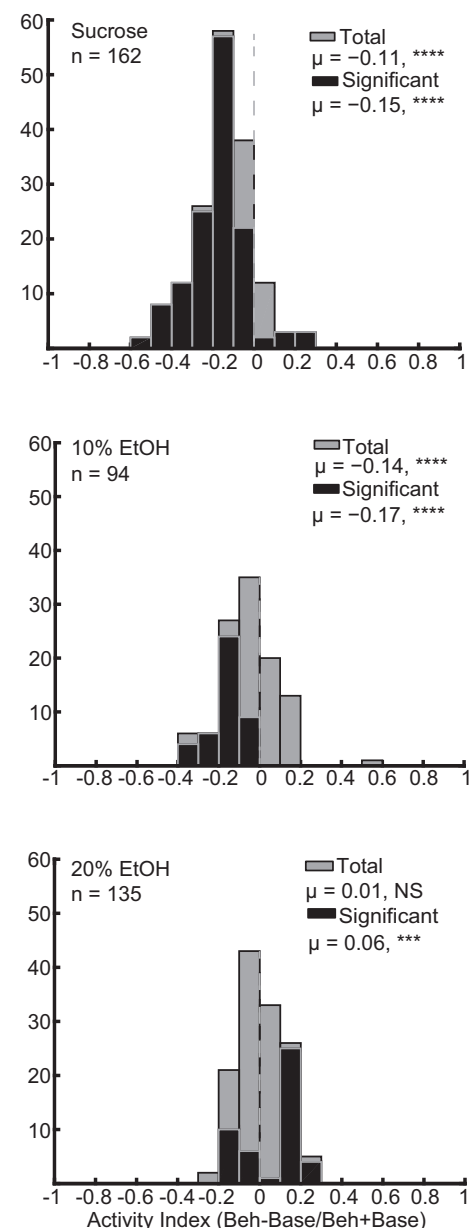

Figure 3. Index calculations for individual OFC neuron activity during cue presentation (left column), reward seeking (middle column), and reward consumption (right column) during sucrose (top row), $10 \% \mathrm{EtOH}$ (middle row), and $20 \% \mathrm{EtOH}$ (bottom row) sessions. Indices calculated as in Materials and Methods. Beh = behavioral epoch; Base = baseline epoch. NS not significant; $* * p<0.01, * * * p<0.001, * * * * p<0.0001$.

shows significant heterogeneity across neuronal responses. To further characterize the degree to which OFC neurons conformed to specific patterns as shown, for example in Figure 2B,C, we characterized, for each neuron, whether the neuron exhibited significant excitation $(+1)$, inhibition $(-1)$, or neither $(0)$ during each of the three epochs (cue, seeking, reward). This was performed for each of the blocked recording sessions (sucrose, 10\% EtOH, 20\% EtOH). These results are shown in Table 1. Unsurprisingly, there was significant heterogeneity, even within outcome category: during sucrose sessions neurons exhibited 15 different response profiles including significant responding during at least one epoch, during $10 \% \mathrm{EtOH}$ sessions neurons exhibited 10 different profiles, and during $20 \% \mathrm{EtOH}$, neurons exhibited 13 different profiles. In all cases, the overall patterns seen in Figures 2, 3 were maintained (primarily inhibition during sucrose reward, etc.). However, response patterns diverged across epochs, virtually tiling potential pattern space. Of interest is the fact that neuronal responses during $20 \%$ self-administration were largely selective for one epoch and did not exhibit complex excitation/inhibition dynamics as observed during sucrose and $10 \% \mathrm{EtOH}$ seeking.
These results suggest that, rather than reporting a single signal during reward seeking, OFC neurons participate in different populations, each encoding different subcomponents of cue-evoked reward seeking.

We also measured changes in baseline activity to determine whether differences across and within blocked session outcomes were reflected in basal OFC firing rate. We found no significant differences in baseline activity (mean firing rate -8 to $-4 \mathrm{~s}$ before trial start) across different sessions (i.e., sucrose vs $10 \% \mathrm{EtOH}$ vs $20 \% \mathrm{EtOH}$ : $F_{(2,435)}=0.65, p=0.53$, ANOVA). We further measured changes in baseline activity across individual sessions for each neuron to determine whether basal activity changed as a function of time, behavior, reward accumulation, etc. Mean pretrial baseline activity (mean firing rate -8 to $-4 \mathrm{~s}$ before trial start) across each session was grouped into four epochs and comparisons were made across epochs. There were no significant differences across epochs in sucrose $\left(F_{(2.597,418.1)}=1.65, p=0.18\right.$, repeated measures ANOVA), $10 \%$ EtOH $\left(F_{(2.075,230.3)}=2.672, p=0.07\right)$, or $20 \% \mathrm{EtOH}\left(F_{(2.807,457.6)}=1.02, p=0.38\right)$. Similar lack of effects was observed if other baseline epochs were 
Table 1: Distribution of response profiles across neurons during blocked sucrose, $10 \%$ EtOH, and $20 \%$ EtOH recording sessions

\begin{tabular}{|c|c|c|c|c|c|c|c|c|c|c|c|}
\hline \multirow[b]{2}{*}{ Cue } & \multicolumn{2}{|c|}{ Sucrose } & \multirow[b]{2}{*}{ \# Ns } & \multicolumn{4}{|c|}{$10 \% \mathrm{EtOH}$} & \multicolumn{4}{|c|}{$20 \% \mathrm{EtOH}$} \\
\hline & Seeking & Reward & & Cue & Seeking & Reward & \# Ns & Cue & Seeking & Reward & \# Ns \\
\hline 0 & 1 & -1 & 43 & 0 & 0 & -1 & 37 & -1 & 0 & 0 & 20 \\
\hline 0 & 0 & -1 & 30 & -1 & 1 & 0 & 17 & 0 & 0 & -1 & 11 \\
\hline-1 & -1 & -1 & 20 & 0 & 1 & -1 & 7 & 1 & 0 & 0 & 10 \\
\hline 0 & -1 & -1 & 16 & -1 & 0 & -1 & 5 & 0 & 0 & 1 & 9 \\
\hline 0 & 1 & 0 & 12 & -1 & -1 & 0 & 4 & 0 & 1 & 0 & 9 \\
\hline 1 & 0 & 0 & 8 & -1 & 1 & -1 & 2 & 1 & 1 & 1 & 8 \\
\hline-1 & 0 & 1 & 4 & -1 & 0 & 0 & 1 & 0 & 1 & 1 & 5 \\
\hline-1 & 1 & -1 & 4 & 0 & -1 & -1 & 1 & 0 & -1 & 1 & 4 \\
\hline-1 & 0 & -1 & 3 & 1 & 0 & 0 & 1 & 1 & 0 & -1 & 3 \\
\hline-1 & 1 & 0 & 2 & 1 & 1 & 0 & 1 & -1 & 0 & -1 & 2 \\
\hline 0 & -1 & 0 & 2 & & & & & 1 & 0 & 1 & 2 \\
\hline-1 & 0 & 0 & 1 & & & & & -1 & -1 & 1 & 1 \\
\hline 0 & 0 & 1 & 1 & & & & & 1 & -1 & 1 & 1 \\
\hline 0 & 1 & 1 & 1 & & & & & & & & \\
\hline 1 & 0 & -1 & 1 & & & & & & & & \\
\hline 0 & 0 & 0 & 14 & 0 & 0 & 0 & 18 & 0 & 0 & 0 & 50 \\
\hline
\end{tabular}

Neuron populations are ordered from those containing most to least members. Category of response to cue, seeking, or reward is demarcated by - 1 (significant inhibition during that epoch), +1 (significant excitation during that epoch), or 0 (no significant activity during that epoch). At the bottom of each section is the number of non-responsive neurons $[0,0,0]$. Any combination of responses not shown in this table was not observed during recording.

analyzed. Together, these data indicate that OFC activity was stable both within sessions and that there were no significant differences in baseline OFC activity across sessions.

As noted in Materials and Methods, we stereotaxically targeted separate electrode bundles to mOFC and IOFC. Although our histologic analysis reliably demonstrated that all recording electrodes were located in OFC, we were not completely confident in our ability to analyze differences in the activity of mOFC versus IOFC neurons based on matching recording channels to histologic reconstruction of electrode placements (Fig. 2A). However, as a rough analysis we separated our recordings into putative mOFC versus IOFC based on stereotaxic placements of electrode arrays, independent of lesion sites, which spanned IOFC, vOFC, and mOFC. Based on this grouping, we found no significant differences in mOFC versus IOFC response indices during sucrose or $10 \%$ $\mathrm{EtOH}$ sessions, nor during cue or seeking epochs during $20 \%$ EtOH sessions (no main effect of mOFC vs IOFC or interaction effect; all $p>0.05$; two-factor ANOVA), although there were significant main effects of outcome in both epochs, in line with the overall findings reported above. During the reward consumption epoch, we found a main effect of mOFC versus IOFC $\left(F_{(1,385)}=4.97\right.$, $p=0.03)$ and a main effect of outcome $\left(F_{(2,385)}=13.55\right.$, $p<0.0001$ ), although no significant interaction effect. Post hoc analyses did not reveal clear effects of medial versus lateral in any specific condition (for example, mOFC vs IOFC during $20 \%$ EtOH). This overall effect appears to be driven primarily by stronger inhibition in mOFC versus IOFC across conditions (sucrose indices, mOFC: -0.17 , IOFC: $-0.13 ; 10 \% \mathrm{EtOH}$ indices, mOFC: -0.13 , IOFC: -0.12 ; $20 \%$ EtOH indices, mOFC: -0.09 , IOFC: -0.03 ). These data are intriguing in the light of previous reports of differential value/preference coding by mOFC versus IOFC neurons (Burton et al., 2014; Lopatina et al., 2016). However, we stress that any conclusions based on these data are tentative because of incomplete histologic confirmation.

\section{Differential OFC signaling during consumption was not related to differential lick behavior}

One potential explanation for the striking differential OFC activity observed during is that, rather than differentially encoding outcome, OFC activity was related to licking behavior. Since reward consumption was shorter for $\mathrm{EtOH}$, particularly $20 \% \mathrm{EtOH}$ trials compared with sucrose trials an argument might be that less OFC inhibition during $20 \%$ EtOH trials was because of shorter consumption epochs. Although this was largely accounted for by performing analyses on trial-by-trial consumption epochs, we performed a number of analyses to verify our conclusions. First, we correlated the trial-to-trial activity index of each neuron with lick duration to determine whether activity scaled with lick duration, using normalized response indices. We found that 11/162 neurons in sucrose, $6 / 171$ neurons in $20 \% \mathrm{EtOH}$, and 6/113 neurons in $10 \% \mathrm{EtOH}$ exhibited significant $(p<0.05)$ correlation with lick duration, indicating that there were minimal influences of lick duration on neural activity. Second, we combined all activity of all neurons in all trials and performed a total correlation between index and duration. We found significant correlations in all of these cases (sucrose: $\rho=0.09$, $p<0.0001 ; 10 \% \mathrm{EtOH}: \rho=-0.06, p=0.029 ; 20 \% \mathrm{EtOH}$ : $\rho=-0.11, p<0.0001)$. We were skeptical of the relevance of these results because of (1) the fact that sucrose and $\mathrm{EtOH}$ conditions had opposing correlation directions, suggesting no real OFC relationship with lick duration and (2) the very small $\rho$ values, suggesting that statistical significance resulted from correlations performed on very large numbers ( $>1000$ per analysis). Third, to assess whether this effect was driven by large numbers of data points, we calculated correlations for each condition on an animal-by-animal basis, reasoning that if this effect 
was valid, we should see it in each animal. Across sucrose recordings, we found significant $(p<0.05)$ correlations between lick duration and OFC activity in 2/16 rats. Across $10 \%$ EtOH sessions, we found significant correlations in $2 / 11$ rats. Across $20 \% \mathrm{EtOH}$ sessions, we found significant correlations in $1 / 12$ rats. Two rats in $20 \% \mathrm{EtOH}$ and one rat in $10 \% \mathrm{EtOH}$ sessions consumed too little $\mathrm{EtOH}$ to permit analysis. We conclude from these findings that there was no relationship between reward consumption duration and degree of suppression of OFC activity. To confirm a lack of relationship between OFC activity and licking in this experiment, we plotted histograms time-locked to licks and lick bouts to determine whether there were peaks in activity as have been observed in previous studies in OFC (Gutierrez et al., 2010) and medial prefrontal cortex (Amarante et al., 2017). We observed no clear time-locked activity and did not pursue further analysis.

Another, related, possible alternate interpretation of differences observed during consumption is that, after the initiation of licking, there is a temporally consistent process of inhibition that occurs for all licking behavior independent of reward, that is truncated by shorter $\mathrm{EtOH}$ licking times thereby precluding observation of significant suppression during $20 \% \mathrm{EtOH}$ consumption. To address this issue, we performed a sliding window analysis using 100 -ms bins to determine when OFC firing was significantly inhibited during consumption relative to baseline. We performed this analysis on sucrose and $20 \% \mathrm{EtOH}$ sessions, as these were the extremes with respect to reward consumption duration and because sucrose responses were strongly down-modulated and $20 \% \mathrm{EtOH}$ responses were not. We calculated, on a neuron-by-neuron basis, the timestamps of the first of two consecutive $100-m s$ bins following the initiation of consumption that reached statistically significant inhibition compared with baseline. We then compared the relationship of this onset of inhibition to lick durations in both sucrose and EtOH. In sucrose sessions, the median latency for inhibition to develop postlick was $0.5 \mathrm{~s}$. This was not different from that seen in the small number of neurons in which inhibition was observed in $20 \% \mathrm{EtOH}$ trials (median $=0.7 \mathrm{~s}$; $p=0.29$, Wilcoxon rank sum). In contrast, the latency of inhibition onset was significantly different, and much shorter than the duration of licking measured in these analyses (sucrose duration median $6.38 \mathrm{~s}$ vs $20 \% \mathrm{EtOH}$ median $5.47 \mathrm{~s}$, all comparisons of inhibition latency vs consumption duration $p<0.0001$; note that durations are slightly different from those shown in Fig. 1 because of inclusion only of trials in which inhibition of activity was measured). Although there was a significant difference between sucrose and $20 \% \mathrm{EtOH}$ consumption duration, this difference did not overlap with the onset of potential inhibition, as seen in sucrose trials and in the small number of significantly inhibited neurons in $\mathrm{EtOH}$ trials. Beyond statistical significance, the overall differences in magnitude $(<1 \mathrm{~s}$ for onset of inhibition vs $>3 \mathrm{~s}$ for duration of consumption) strongly indicate that there was ample consumption of $20 \% \mathrm{EtOH}$ to permit possible inhibition of OFC activity, if it were to occur. Instead, we conclude that inhibition of OFC activity during sucrose consumption was not present in the majority of neurons recorded during $20 \% \mathrm{EtOH}$ consumption, independent of duration of licking.

\section{$20 \%$ EtOH seeking was strongly associated with homecage EtOH preference}

Rats were separated into HDs and LDs based on average $\mathrm{g} / \mathrm{kg} 20 \% \mathrm{EtOH}$ consumed during homecage intermittent access (see Materials and Methods). Of the 16 rats studied in sucrose and $20 \% \mathrm{EtOH}$ conditions, seven were classified as LD, and nine were classified as HD. Of the 12 rats studied in sucrose, $10 \% \mathrm{EtOH}$, and $20 \% \mathrm{EtOH}$ conditions, five were classified as LD, and seven were classified as HD. HD rats escalated $20 \%$ EtOH consumption across intermittent access sessions, whereas $L D$ rats did not (two-way ANOVA; main effect of day: $F_{(1,11)}=$ 2.77, $p=0.002$; main effect of HD/LD: $F_{(1,1)}=127.3$, $p<0.0001$; interaction $F_{(1,11)}=2.93, p=0.001$; Fig. $\left.4 A\right)$. Based on mean 24-h consumption in the last $3 \mathrm{~d}$ of homecage intermittent access, HD rats consumed significantly more EtOH than LD rats (HD: $5.0 \pm 0.45 \mathrm{~g} / \mathrm{kg}$ ); LD: $2.35 \pm$ $0.13 \mathrm{~g} / \mathrm{kg} ; U=5 p<0.0001$, Mann-Whitney).

During operant testing, HD and LD rats exhibited significant differences in $\mathrm{EtOH}$ seeking and consumption (Fig. $4 B, C)$. $\mathrm{HD}$ rats received significantly more $20 \% \mathrm{EtOH}$ rewards than LD rats $(U=5, p=0.004$; Fig. $4 B$, red), but there were no differences in seeking for sucrose or $10 \%$ EtOH (sucrose: $U=31, p=1 ; 10 \%$ EtOH: $U=14, p=0.42$ ). $\mathrm{HD}$ rats also consumed more $20 \% \mathrm{EtOH}$ than LD, measured by the duration of licking $(U=3, p=0.0006$; Fig. $4 C$, red). There were no differences between HD and LD rats with respect to consumption of sucrose or $10 \% \mathrm{EtOH}$ (sucrose: $U=29, p=0.84 ; 10 \% \mathrm{EtOH}: U=20, p=0.16$ ). Average $\mathrm{g} / \mathrm{kg}$ of $20 \% \mathrm{EtOH}$ consumed on the final $3 \mathrm{~d}$ of intermittent access was also correlated with duration of reward consumption during each rewarded trial for $20 \%$ $\mathrm{EtOH}(r=0.82, p<0.0001)$ and $10 \% \mathrm{EtOH}(r=0.51$, $p=0.007$ ), but not sucrose: $r=0.15, p=0.99$ ).

\section{OFC activity during $10 \%$ and $20 \%$ EtOH seeking was associated with homecage EtOH preference}

OFC neural activity was significantly different between $\mathrm{HD}$ and LD rats during EtOH seeking. There were no significant differences in OFC activity during sucrose cue presentation, reward seeking, and consumption in HD versus LD rats (cue: $U=3128, p=0.71$; seeking: $U=3126$, $p=0.70$; reward: $U=3010, p=0.44$, Mann-Whitney; Fig. $4 D$ ). In contrast, there were significant differences in OFC activity between HD versus LD rats during both $10 \%$ and $20 \% \mathrm{EtOH}$ trials. OFC neurons in HD rats exhibited response profiles more similar to that seen during sucrose seeking (Fig. 4E,F), whereas OFC responses were significantly suppressed in LD rats. These differences were significant for all epochs in $10 \% \mathrm{EtOH}$ sessions (cue: $U=639, p=0.0007$; seeking: $U=870, p=0.0014$; consumption: $U=416, p<0.0001$ ), and during cue and seeking epochs during $20 \% \mathrm{EtOH}$ sessions (cue: $U=2204$, $p=0.001$; seeking: $U=1028, p=0.0004$; consumption: $U=1633, p=0.44)$. Consumption differences during $20 \%$ 

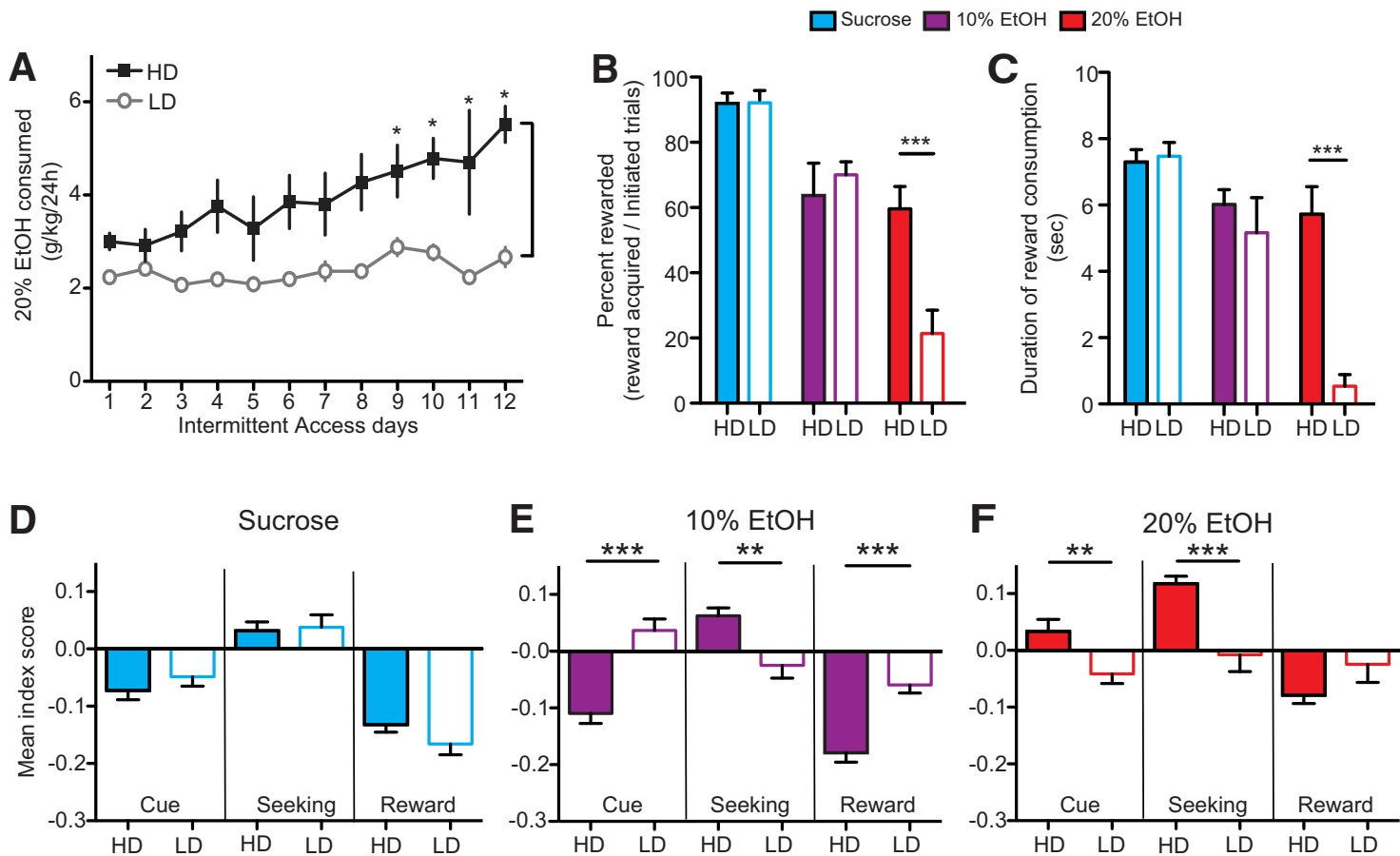

Figure 4. Rats were separated into HDs and LDs based on homecage EtOH consumption (see Materials and Methods). $\boldsymbol{A}$, HD rats exhibited significant escalation over the course of homecage intermittent access to EtOH whereas LD rats did not. $\boldsymbol{B}$, HD rats (filled bars) completed significantly more rewarded trials for $20 \% \mathrm{EtOH}$ (red) than LD rats (open bars), but there were no differences for sucrose (blue) or $10 \% \mathrm{EtOH}$ (purple) rewarded trials. $\boldsymbol{C}$, HD rats consumed significantly more $20 \%$ EtOH than LD rats, measured by lick duration, but there were no differences in consumption of sucrose or $10 \% \mathrm{EtOH}$. $\boldsymbol{D}$, OFC neuronal activity in HD versus LD rats was similar during sucrose cues, seeking, and consumption but was significantly different during cues, seeking, and consumption of $10 \% \mathrm{EtOH}(\boldsymbol{E})$ and during cues and seeking of $20 \% \mathrm{EtOH}(\boldsymbol{F})$. Overall strength of OFC signaling (either excitation or inhibition) was suppressed in LD rats relative to $\mathrm{HD}$ rats in $\mathrm{EtOH}$ sessions; $* p<0.05, * * p<0.01, * * * p<0.001$.

EtOH sessions exhibited a similar HD/LD pattern as during $10 \% \mathrm{EtOH}$ sessions, but were statistically underpowered during consumption for LD rats because of a limited number of $20 \%$ reward acquisitions by this population (Fig. 4B).

\section{OFC activity during sucrose and $20 \% \mathrm{EtOH}$ interleaved trials was strongly associated with homecage EtOH preference}

In order to characterize how the same OFC neurons fired during sucrose and EtOH seeking, we also recorded OFC activity during sessions in which sucrose and $20 \% \mathrm{EtOH}$ trials were pseudorandomly interleaved (Materials and Methods). During interleaved sessions HD and LD rats exhibited similar proportions of sucrose and $20 \% \mathrm{EtOH}$ rewarded trials, and similar duration of sucrose consumption ( $p>0.05$; Fig. $5 A, B$ ), but LD rats consumed significantly less $\mathrm{EtOH}$ measured by duration of consumption $(U=9$, $p=0.007$; Fig. 5B)

OFC activity was significantly changed during cue, seeking, and reward consumption epochs. Figure $5 C$ shows activity of an example neuron recorded in sucrose and $\mathrm{EtOH}$ trials. Across the population of OFC neurons, response indices were highly correlated in sucrose and EtOH trials (Fig. 5D-F). Neurons exhibited strong, significant biases toward inhibition during cue presentation $\left(\chi^{2}(1)=27.71, p=0.0008 ; \chi^{2}\right)$, excitation during reward seeking $\left(\chi^{2}(1)=24.01, p<0.0001\right)$ and inhibition during reward consumption $\left(\chi^{2}(1)=40.51, p<0.0001\right)$, in line with responses recorded during blocked conditions. Although a subset of neurons exhibited significant modulation in both sucrose and $\mathrm{EtOH}$ trials, the majority of neurons with significant changes in firing rate exhibited selectivity for sucrose or $\mathrm{EtOH}$. As with neurons recorded during the blocked conditions, we observed significant heterogeneity in response profiles across neurons (Table 2). Although the variability does appear to be greater during interleaved conditions, this is to some degree driven by the increased numbers of parameters used to classify neurons (six vs three) and there are large populations of neurons with specific types of encoding in one subcondition or the other (e.g., inhibition during sucrose consumption). Thus, although the overall OFC population treated sucrose and $\mathrm{EtOH}$ as points in a continuum of rewards, as evidenced by correlated activity, individual neurons exhibited a diverse array of epoch-specific response biases and selective activity for sucrose or $\mathrm{EtOH}$.

OFC activity during interleaved trials was strikingly different in HD versus LD rats (Fig. 5G,H). In HD rats, OFC activity during sucrose and $20 \%$ EtOH trials followed a similar pattern: inhibition during cue presentation, excitation during seeking, and inhibition during consumption, similar to that seen during blocked sessions. In contrast, LD rat OFC neurons exhibited suppressed responses during all epochs. During cue presentation there was a 

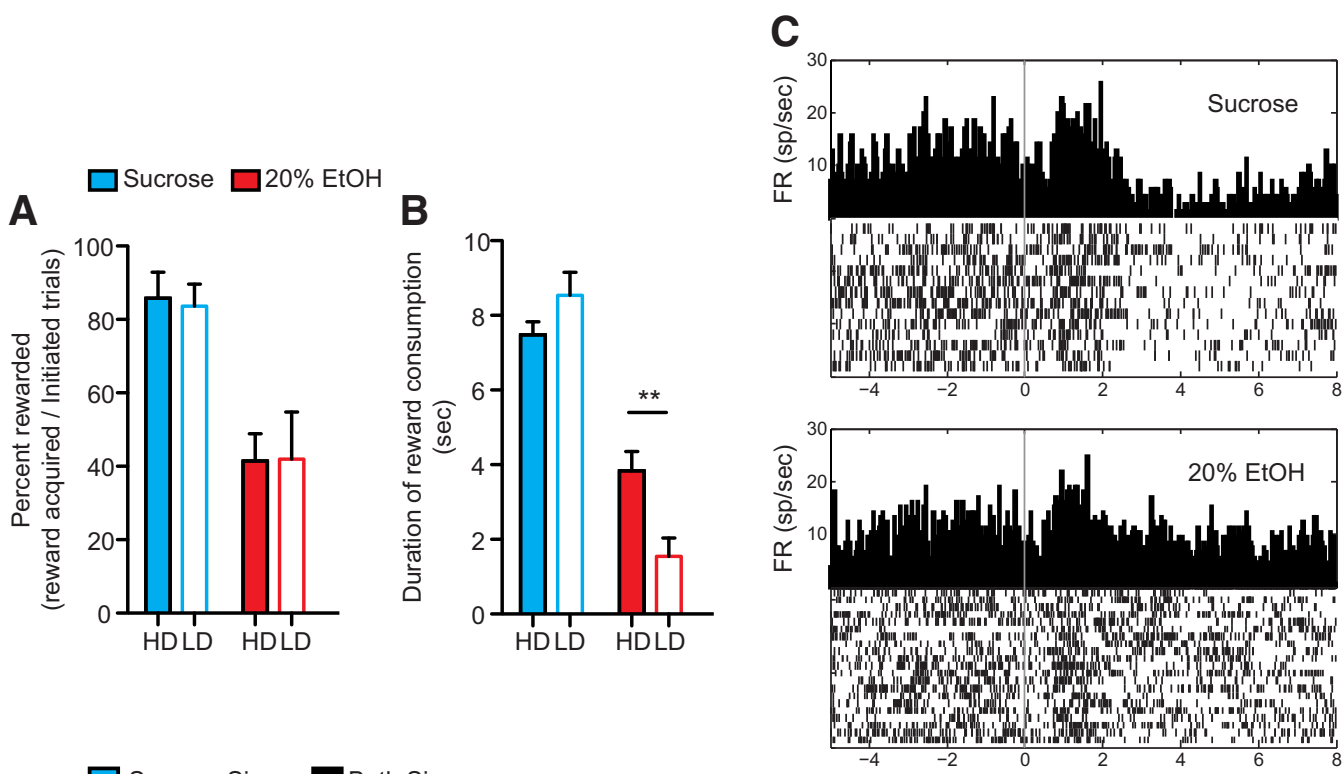
Sucrose Sig.
Both Sig

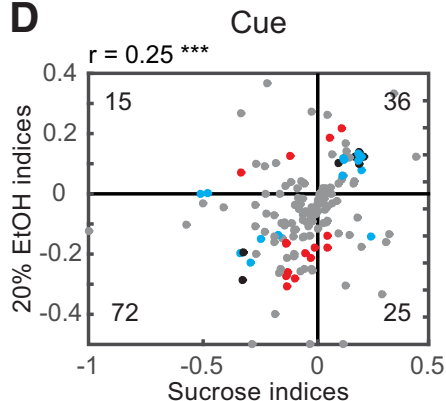

E

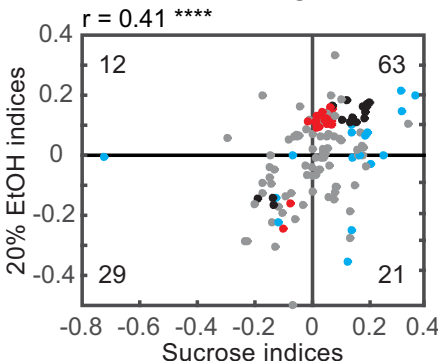

$\mathbf{F}$
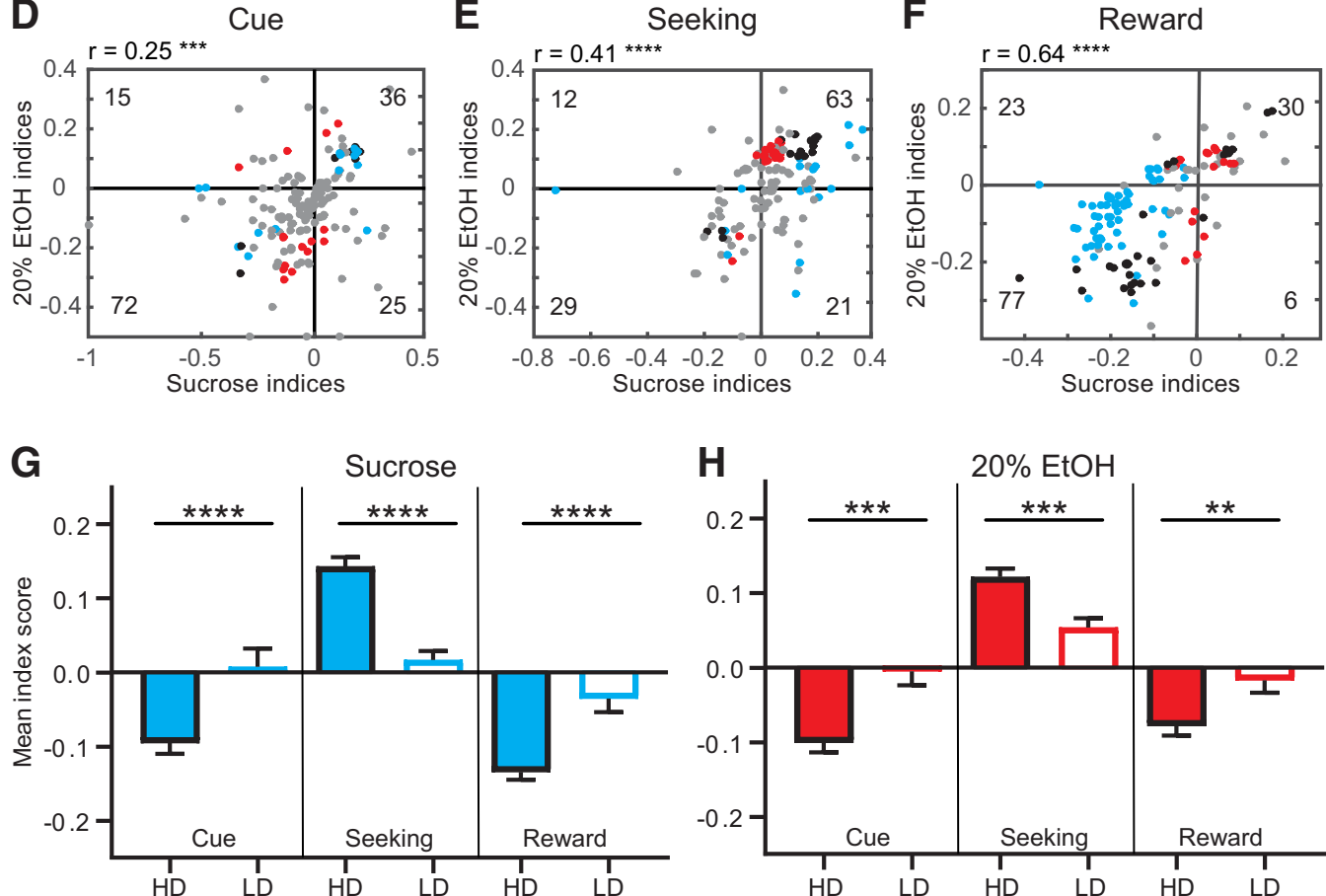

Figure 5. OFC neuronal activity was recorded during interleaved trials of $20 \% \mathrm{EtOH}$ and sucrose. $\boldsymbol{A}$, During interleaved sessions, HD (filled bars) and LD (open bars) rats completed similar numbers of sucrose (blue) and 20\% EtOH (red) trials. $\boldsymbol{B}$, However, LD rats consumed significantly less $20 \% \mathrm{EtOH}$ than $\mathrm{HD}$ rats. $\mathbf{C}$, Example of activity from a single neuron in sucrose (top) and $20 \% \mathrm{EtOH}$ (bottom) conditions. $\boldsymbol{D}-\boldsymbol{F}$, Sucrose/EtOH index profiles for individual neurons recorded during interleaved trials of sucrose and $20 \%$ $\mathrm{EtOH}$ seeking. Recording the same neuron in both conditions allowed characterization of sucrose/EtOH index profiles for each neuron. Indices were calculated as in blocked conditions. Each dot represents sucrose $/ 20 \% \mathrm{EtOH}$ index combination for each neuron during cue ( $\boldsymbol{D}, n=156$ neurons), seeking ( $\boldsymbol{E}, n=137$ neurons), and reward ( $\boldsymbol{F}, n=137$ neurons). Only neurons in which seeking and consumption trials were performed for both sucrose and $20 \% \mathrm{EtOH}$ were included in seeking and reward plots; $r$ and $p$ values indicate significant correlations across all neurons in sucrose and EtOH trials, despite a bias toward significant selectivity in encoding of one versus another outcome. Blue, red, black, and gray dots represent neurons significantly activated/inhibited during sucrose conditions only, $20 \% \mathrm{EtOH}$ only, both, and neither condition, respectively. Although a subset of neurons exhibited significant modulation in both sucrose and EtOH trials (black dots: 8 in response to cue, 17 during seeking, and 29 during consumption), the majority of significantly-influenced neurons exhibited selectivity for sucrose (blue dots: 14 cue, 16 seeking, and $58 \mathrm{consumption)}$ or EtOH (red dots: 15 cue, 22 seeking, and 19 consumption). Numbers in each quadrant indicate numbers of neurons falling within that 
continued

quadrant. Neurons with an index of 0 in one axis were not counted in quadrant totals. Most neurons showed inhibition during sucrose and $\mathrm{EtOH}$ cues, excitation during sucrose and $\mathrm{EtOH}$ seeking, and inhibition during sucrose and EtOH consumption, in line with patterns observed during blocked conditions. G, $\boldsymbol{H}$, OFC activity was similar in sucrose $(\boldsymbol{G})$ and $20 \% \mathrm{EtOH}(\boldsymbol{H})$ trials in $\mathrm{HD}$ rats, but activity of OFC neurons in LD rats was again suppressed relative to activity of those in HD rats. This was true for neuronal responses to the cue, during reward seeking, and during sucrose/EtOH consumption; $* * p<0.01, * * * p<0.001, * * * * p<0.0001$.

significant main effect of preference $\left(F_{(1,135)}=20.51\right.$, $p<0.0001$; two-way mixed ANOVA). During the seeking epoch, there was a significant main effect of preference $\left(F_{(1,135)}=40.99, p<0.0001\right)$ and significant interaction

Table 2: Distribution of response profiles across neurons during interleaved sucrose, $10 \% \mathrm{EtOH}$, and $20 \% \mathrm{EtOH}$ recording sessions

\begin{tabular}{|c|c|c|c|c|c|c|}
\hline \multirow[b]{2}{*}{ Cue } & \multicolumn{2}{|c|}{ Sucrose } & \multicolumn{3}{|c|}{$20 \% \mathrm{EtOH}$} & \multirow[b]{2}{*}{ \# Ns } \\
\hline & Seeking & Reward & Cue & Seeking & Reward & \\
\hline 0 & 0 & -1 & 0 & 0 & 0 & 28 \\
\hline 0 & 0 & -1 & 0 & 1 & 0 & 10 \\
\hline 0 & 0 & -1 & 0 & 0 & -1 & 9 \\
\hline 0 & 1 & -1 & 0 & 0 & 0 & 8 \\
\hline 0 & 0 & 0 & 0 & 1 & 1 & 4 \\
\hline 1 & 1 & 1 & 1 & 1 & 1 & 4 \\
\hline 0 & 0 & -1 & -1 & 1 & 0 & 3 \\
\hline 0 & 1 & -1 & 0 & 0 & -1 & 3 \\
\hline 0 & 1 & 0 & 0 & 1 & 0 & 3 \\
\hline-1 & 0 & -1 & -1 & 0 & 0 & 2 \\
\hline-1 & 0 & -1 & 0 & 0 & -1 & 2 \\
\hline 0 & 0 & -1 & -1 & 0 & -1 & 2 \\
\hline 0 & 0 & -1 & -1 & 0 & 0 & 2 \\
\hline 0 & 0 & -1 & 0 & 1 & 1 & 2 \\
\hline 0 & 0 & 1 & 0 & 0 & 1 & 2 \\
\hline 0 & 1 & -1 & 0 & 1 & 0 & 2 \\
\hline 1 & 0 & 0 & 0 & 0 & 1 & 2 \\
\hline 1 & 0 & 0 & 1 & 0 & 1 & 2 \\
\hline 1 & 1 & 0 & 1 & 1 & 1 & 2 \\
\hline-1 & 0 & -1 & -1 & 0 & -1 & 1 \\
\hline-1 & 0 & 0 & -1 & 0 & 0 & 1 \\
\hline-1 & 0 & 0 & 0 & 0 & 0 & 1 \\
\hline-1 & 0 & 0 & 0 & 0 & 1 & 1 \\
\hline 0 & -1 & -1 & -1 & -1 & 0 & 1 \\
\hline 0 & -1 & -1 & -1 & 0 & 0 & 1 \\
\hline 0 & -1 & -1 & 0 & 0 & -1 & 1 \\
\hline 0 & -1 & 0 & 0 & -1 & -1 & 1 \\
\hline 0 & -1 & 0 & 0 & 0 & -1 & 1 \\
\hline 0 & -1 & 0 & 1 & -1 & -1 & 1 \\
\hline 0 & -1 & 1 & 0 & -1 & -1 & 1 \\
\hline 0 & 0 & 0 & -1 & 0 & 0 & 1 \\
\hline 0 & 0 & 0 & 0 & -1 & -1 & 1 \\
\hline 0 & 0 & 0 & 0 & 0 & -1 & 1 \\
\hline 0 & 0 & 0 & 0 & 0 & 1 & 1 \\
\hline 0 & 0 & 0 & 0 & 1 & 0 & 1 \\
\hline 0 & 1 & -1 & 0 & 1 & 1 & 1 \\
\hline 0 & 1 & 0 & 0 & 1 & 1 & 1 \\
\hline 0 & 1 & 0 & 1 & 0 & 0 & 1 \\
\hline 1 & 0 & 0 & 0 & 0 & 0 & 1 \\
\hline 1 & 1 & 0 & 0 & 0 & 0 & 1 \\
\hline 1 & 1 & 0 & 0 & 1 & 1 & 1 \\
\hline 1 & 1 & 1 & 0 & 1 & 1 & 1 \\
\hline 0 & 0 & 0 & 0 & 0 & 0 & 19 \\
\hline
\end{tabular}

Format is the same as Table 1, except that the same neurons were recorded in sucrose $/ 20 \% \mathrm{EtOH}$ interleaved sessions and neurons are categorized based on responses in both trial types. effect between preference and reward type $\left(F_{(1,135)}=13.41\right.$, $p=0.0003)$. Finally, during the reward consumption epoch, there was a significant main effect of preference $\left(F_{(1,135)}=19.73, p<0.0001\right)$, a significant main effect of reward type $\left(F_{(1,135)}=17.56, p<0.0001\right)$, and a significant interaction effect $\left(F_{(1,135)}=4.61, p=0.0336\right)$. These results demonstrate a clear relationship between $\mathrm{EtOH}$ preference and OFC activity in HD versus LD rats. OFC neurons in HD rats responded more similarly for sucrose and $\mathrm{EtOH}$, encoding both as palatable rewards. In contrast, OFC neurons in $\mathrm{LD}$ rats responded weakly for both sucrose and $\mathrm{EtOH}$, suggesting a possible suppressive effect of the presence of EtOH during interleaved sessions.

\section{Discussion}

Here, we demonstrated that OFC neuronal activity encodes individual preferences for alcohol. OFC activity was significantly increased or decreased during both sucrose and alcohol seeking, but the features of their alcohol-associated responses were directly related to alcohol palatability and homecage drinking. OFC neuronal activity was most strongly affected in sucrose trials, followed by $10 \%$ $\mathrm{EtOH}$ and $20 \% \mathrm{EtOH}$, in line with behavioral preferences. Furthermore, OFC neurons in HD rats exhibited stronger responses during $\mathrm{EtOH}$ seeking than in LD rats, supporting the hypothesis that individual differences in relative preference for natural and drug rewards are encoded in OFC (Tremblay and Schultz, 1999; Padoa-Schioppa and Assad, 2006; Schultz, 2010; Guillem and Ahmed, 2018b; Guillem et al., 2018) and demonstrating this in the context of alcohol seeking. Importantly, differential OFC activity across individuals and outcomes cannot be explained exclusively by behavioral measures such as mechanics of reward consumption. Analysis of consumption-associated activity was based on periods of time when the rats were consuming sucrose or EtOH, meaning that consumption-associated differences in activity across outcomes or individuals were not influenced by periods of non-consumption. Along these lines, differential OFC activity could not be explained by individual variation in consumption duration, since, in some cases, rats with equivalent consumption behaviors exhibited significantly different OFC neuronal responses [e.g., 10\% EtOH in HD vs LD (Fig. 4) and sucrose in HD vs LD (Fig. 5)]. This was formally supported by statistical analysis showing very little correlation between OFC activity and reward consumption duration. Our results indicate that OFC function is fundamentally different in high versus low alcohol-preferring individuals. They further suggest that OFC neurons in alcohol use disorder-prone or -diagnosed individuals may respond more robustly to alcohol and alcohol cues, conferring enhanced value and driving enhanced alcohol motivated behavior. Although this is somewhat speculative based on 
our current results, our data, along with human research to date, suggest that OFC should continue to be investigated in this context.

Our data are well aligned with previous work. In humans, OFC is activated during alcohol craving (Myrick et al., 2004, 2008; Lukas et al., 2013; Schacht et al., 2013a,b, 2014), and endgenous opioid release is induced by alcohol consumption in heavy drinkers (Mitchell et al., 2012). Inactivation of OFC in mice exposed to chronic EtOH vapor increased consumption of quinine-adulterated EtOH (den Hartog et al., 2016), and IOFC lesions increased alcohol consumption in rats (Ray et al., 2018), both of which suggest a regulatory role for OFC in alcohol use. This is supported by reports that chronic EtOH disrupts goal-directed behavior and suppresses OFC firing in vitro and that DREADD activation of OFC activity restores goal-directed behavior (Renteria et al., 2018). OFC inactivation in rats decreases cued or contextdriven reinstatement of EtOH seeking, arguing that OFC activity may facilitate EtOH seeking (Bianchi et al., 2018). These latter results indicate that OFC contributes to EtOH seeking, in line with preference-associated differences observed here. Whether increased OFC activity induces or suppresses alcohol seeking may depend on a number of factors such as species, withdrawal state, and OFC subregion.

There is also an impact of acute and chronic EtOH on structure and function of OFC neurons. Chronic EtOH increased spine density in OFC neurons (McGuier et al., 2015; but see Holmes et al., 2012; DePoy et al., 2013). Acute EtOH decreased (Badanich et al., 2013a) and chronic EtOH exposure increased (Nimitvilai et al., 2016, 2017a) or decreased (Nimitvilai et al., 2017b; Renteria et al., 2018) OFC neuronal excitability. As with behavioral studies, there is some variability across species and paradigms, but there is a clear influence of $\mathrm{EtOH}$ on OFC structure and function, in line with the behavioral physiological results reported here.

OFC neuronal activity tracked individual preference, in some cases independent of operant behavior. During blocked $10 \% \mathrm{EtOH}$ trials, HD and LD rats exhibited no significant differences in $\mathrm{EtOH}$ seeking or consumption (Fig. 4B,C). However, OFC activity was significantly different in HD versus LD rats in these trials (Fig. 4E). OFC neurons fired more strongly in $\mathrm{HD}$ rats, and the patterns of responses in HD rats were similar in sucrose and $10 \%$ EtOH conditions (Fig. 4D,E). This discontinuity between OFC activity and behavior demonstrates a stronger role in encoding alcohol preference versus seeking behavior. At the same time, the effects of preference on OFC activity during $20 \%$ EtOH seeking mapped clearly onto behavior. $\mathrm{HD}$ rats were more highly motivated than LD rats during both blocked and interleaved 20\% EtOH trials (Figs. 4B, $C, 5 B$ ), and OFC activity changes were stronger in HD than LD rats during these sessions (Figs. 4F, $5 H$ ). During interleaved sessions, OFC activity was also suppressed in LD rats during sucrose trials (Fig. 5G), again in contrast with no differences in sucrose seeking behavior (Fig. 5A). One possible explanation may be that subjective value of sucrose may have been compromised for LD rats by the presence of EtOH trials during sucrose sessions, although other explanations are possible as well. Intriguingly, if this is true, this indicates that OFC activity was different across individuals (suppressed in LD rats) although behavior was consistent, thereby potentially dissociating OFC encoding of preference/value (here demonstrated by homecage alcohol preference) from behavior, potentially driven by alternate brain systems. Although speculative given the present results, these data point to an important future study investigating potential dissociations between behavioral versus neural representations of preference or value.

We note a number of conceptual limitations in this study. We were interested in how OFC neuronal activity differed based on differences in motivation to consume $\mathrm{EtOH}$. We use the term individual preference as a measure of willingness to intake alcohol, measured behaviorally, but we note that preference is frequently characterized by measurements such as comparing $\mathrm{EtOH}$ versus water intake. Because we did not perform simultaneous two-bottle $\mathrm{EtOH}$ versus water measurements, we cannot conclusively say that the differences in alcohol consumption are preference, per se, but we note that individual variability in alcohol intake, including variability that arises over time during intermittent homecage access, is typically concurrent with alcohol preference as measured in two-bottle tests. We also note that individual differences in OFC activity (or differences in HD vs LD rats) may have been driven by differences in overall EtOH intake history. This fascinating question of innate versus exposure-driven differences in $\mathrm{EtOH}$ motivation is something that we are currently exploring. We also acknowledge that levels of drinking performed by high drinking rats here are lower than that observed using other techniques such as high-drinking rat strains, or chronic intermittent exposure to EtOH vapor. Although high drinking rats frequently consumed high levels of EtOH (in some cases over $10 \mathrm{~g} / \mathrm{kg} / 24 \mathrm{~h}$ ), and were, on average, in line with previous reports of high drinking in outbred rats (Simms et al., 2008; George et al., 2012; Carnicella et al., 2014; Momeni and Roman, 2014; Spoelder et al., 2015), we cannot say for sure that drinking in this study was driven by pharmacological elements of $\mathrm{EtOH}$ as opposed to taste or palatability aspects, particularly given that we did not measure blood EtOH levels. Given the role of the OFC in processing taste and taste preferences (Rolls, 2015), this issue is something that should be addressed in future studies.

Together, these results support the hypothesis that OFC encodes outcome preference or value. The data are aligned with models of inferred value representation (Jones et al., 2012; Baltz et al., 2018; Sadacca et al., 2018). Neural responses to sucrose were suppressed in LD rats by the possibility of receiving $20 \% \mathrm{EtOH}$ in interleaved sessions, potentially indicating an updating of cue/outcome representation when the less-preferred alcohol was an option. However, our data also support the representation of cached value in OFC activity. These preference-associated signals were most strongly associated with homecage drinkingdriven alcohol preference independent of operant alcohol seeking behaviors. These potentially conflicting representations may derive from the effect of alcohol history on HD 
versus $\mathrm{LD}$ rats. In $\mathrm{HD}$ rats, a history of $\mathrm{EtOH}$ exposure may have produced a more rigid OFC representation of cached value and habitual behavior, resulting in similar encoding of sucrose and $\mathrm{EtOH}$ and overall greater motivation for $\mathrm{EtOH}$. This is directly in line with recent results demonstrating chronic alcohol-induced disruption of OFC-dependent goaldirected behavior (Renteria et al., 2018). In contrast, LD rats maintain flexible behavior (e.g., sucrose consumption, alcohol avoidance) due in part to changes in OFC activity depending on the outcome. More work needs to be done to fully explain the nature of alcohol preference encoding, such as including other types of outcomes (water, aversive outcomes such as quinine, etc.). Furthermore, understanding cause and effect will be of substantial future importance, e.g., do HD rats have different OFC activity than LD rats because of some genetic or developmental feature or is it a consequence of high levels of alcohol drinking? Similar issues have been raised in studies of dopamine neuron encoding of individual alcohol preference in mice (Juarez et al., 2017).

An additional question for future work is the degree to which differential outcome encoding is reflected during cue presentations, actions, or acquisition of the outcome itself. Many previous studies have shown OFC responses to cues or actions associated with different outcomes, that vary depending on the outcome itself (Stalnaker et al., 2015; Sharpe and Schoenbaum, 2016). In some cases, this may related to preference (Tremblay and Schultz, 1999; Padoa-Schioppa and Assad, 2006; Schultz, 2010; Guillem and Ahmed, 2018b; Guillem et al., 2018) or, in others, it may relate to outcome identity (McDannald et al., 2014b). This is of interest in the context of the current findings, in which some differences were selective excitatory responses (during seeking) whereas others were inhibitory (during consumption). One possible explanation that demands further investigation is that different populations of OFC neurons encode cues versus actions versus outcomes themselves and that dynamics (relationship of excitation to inhibition) vary at each stage of the behavior. This hypothesis is supported by the observed heterogeneity in the neuronal populations recorded here (Tables 1, 2).

Based on these and related data, it is clear that a neural circuit framework including multiple neural networks should be considered to address these issues. As demonstrated by our work and others, characterization of individual variability in neural circuit representation of alcohol preference has relevance to a better understanding of the neural basis of alcohol use and potentially even how differential alcohol use contributes to alcohol use disorder.

\section{References}

Amarante LM, Caetano MS, Laubach M (2017) Medial frontal theta is entrained to rewarded actions. J Neurosci 37:10757-10769.

Badanich KA, Becker HC, Woodward JJ (2011) Effects of chronic intermittent ethanol exposure on orbitofrontal and medial prefrontal cortex-dependent behaviors in mice. Behav Neurosci 125:879891.

Badanich KA, Mulholland PJ, Beckley JT, Trantham-Davidson H, Woodward JJ (2013a) Ethanol reduces neuronal excitability of lateral orbitofrontal cortex neurons via a glycine receptor dependent mechanism. Neuropsychopharmacology 38:1176-1188.

Badanich KA, Mulholland PJ, Beckley JT, Trantham-Davidson H, Woodward JJ (2013b) Ethanol reduces neuronal excitability of lateral orbitofrontal cortex neurons via a glycine receptor dependent mechanism. Neuropsychopharmacol 38:1176-1188.

Baeg EH, Jackson ME, Jedema HP, Bradberry CW (2009) Orbitofrontal and anterior cingulate cortex neurons selectively process cocaine-associated environmental cues in the rhesus monkey. J Neurosci 29:11619-11627.

Balleine BW, Leung BK, Ostlund SB (2011) The orbitofrontal cortex, predicted value, and choice. Ann NY Acad Sci 1239:43-50.

Baltz ET, Yalcinbas EA, Renteria R, Gremel CM (2018) Orbital frontal cortex updates state-induced value change for decision-making. Elife 7:e35988.

Bianchi PC, Carneiro de Oliveira PE, Palombo P, Leão RM, CogoMoreira H, Planeta CDS, Cruz FC (2018) Functional inactivation of the orbitofrontal cortex disrupts context-induced reinstatement of alcohol seeking in rats. Drug Alcohol Depend 186:102-112.

Burton AC, Kashtelyan V, Bryden DW, Roesch MR (2014) Increased firing to cues that predict low-value reward in the medial orbitofrontal cortex. Cereb Cortex 24:3310-3321.

Carnicella S, Ron D, Barak S (2014) Intermittent ethanol access schedule in rats as a preclinical model of alcohol abuse. Alcohol 48:243-252.

Dalley JW, Cardinal RN, Robbins TW (2004) Prefrontal executive and cognitive functions in rodents: neural and neurochemical substrates. Neurosci Biobehav Rev 28:771-784.

den Hartog C, Zamudio-Bulcock P, Nimitvilai S, Gilstrap M, Eaton B, Fedarovich H, Motts A, Woodward JJ (2016) Inactivation of the lateral orbitofrontal cortex increases drinking in ethanol-dependent but not non-dependent mice. Neuropharmacology 107:451-459.

DePoy L, Daut R, Brigman JL, MacPherson K, Crowley N, GunduzCinar O, Pickens CL, Cinar R, Saksida LM, Kunos G, Lovinger DM, Bussey TJ, Camp MC, Holmes A (2013) Chronic alcohol produces neuroadaptations to prime dorsal striatal learning. Proc Natl Acad Sci USA 110:14783-14788.

Dom G, Sabbe B, Hulstijn W, van den Brink W (2005) Substance use disorders and the orbitofrontal cortex: systematic review of behavioural decision-making and neuroimaging studies. Br J Psychiatry 187:209-220.

Everitt BJ, Hutcheson DM, Ersche KD, Pelloux Y, Dalley JW, Robbins TW (2007) The orbital prefrontal cortex and drug addiction in laboratory animals and humans. Ann NY Acad Sci 1121:576-597.

Fettes P, Schulze L, Downar J (2017) Cortico-striatal-thalamic loop circuits of the orbitofrontal cortex: promising therapeutic targets in psychiatric illness. Front Syst Neurosci 11:25.

Garavan H, Pankiewicz J, Bloom A, Cho JK, Sperry L, Ross TJ, Salmeron BJ, Risinger R, Kelley D, Stein EA (2000) Cue-induced cocaine craving: neuroanatomical specificity for drug users and drug stimuli. Am J Psychiatry 157:1789-1798.

George O, Sanders C, Freiling J, Grigoryan E, Vu S, Allen CD, Crawford E, Mandyam CD, Koob GF (2012) Recruitment of medial prefrontal cortex neurons during alcohol withdrawal predicts cognitive impairment and excessive alcohol drinking. Proc Natl Acad Sci USA 109:18156-18161.

Guillem K, Ahmed SH (2018a) A neuronal population code for resemblance between drug and nondrug reward outcomes in the orbitofrontal cortex. Brain Struct Funct 224:883-890.

Guillem K, Ahmed SH (2018b) Preference for cocaine is represented in the orbitofrontal cortex by an increased proportion of cocaine use-coding neurons. Cereb Cortex 28:819-832.

Guillem K, Kravitz AV, Moorman DE, Peoples LL (2010) Orbitofrontal and insular cortex: neural responses to cocaine-associated cues and cocaine self-administration. Synapse 64:1-13.

Guillem K, Brenot V, Durand A, Ahmed SH (2018) Neuronal representation of individual heroin choices in the orbitofrontal cortex. Addict Biol 23:880-888. 
Gutierrez R, Simon SA, Nicolelis MA (2010) Licking-induced synchrony in the taste-reward circuit improves cue discrimination during learning. J Neurosci 30:287-303.

Holmes A, Fitzgerald PJ, MacPherson KP, DeBrouse L, Colacicco G, Flynn SM, Masneuf S, Pleil KE, Li C, Marcinkiewcz CA, Kash TL, Gunduz-Cinar O, Camp M (2012) Chronic alcohol remodels prefrontal neurons and disrupts NMDAR-mediated fear extinction encoding. Nat Neurosci 15:1359-1361.

Izquierdo A (2017) Functional heterogeneity within rat orbitofrontal cortex in reward learning and decision making. J Neurosci 37:10529-10540.

Jones JL, Esber GR, McDannald MA, Gruber AJ, Hernandez A, Mirenzi A, Schoenbaum G (2012) Orbitofrontal cortex supports behavior and learning using inferred but not cached values. Science 338:953-956.

Juarez B, Morel C, Ku SM, Liu Y, Zhang H, Montgomery S, Gregoire $\mathrm{H}$, Ribeiro E, Crumiller M, Roman-Ortiz C, Walsh JJ, Jackson K, Croote DE, Zhu Y, Zhang S, Vendruscolo LF, Edwards S, Roberts A, Hodes GE, Lu Y, et al. (2017) Midbrain circuit regulation of individual alcohol drinking behaviors in mice. Nat Commun 8:2220.

Jupp B, Krstew E, Dezsi G, Lawrence AJ (2011) Discrete cue-conditioned alcohol-seeking after protracted abstinence: pattern of neural activation and involvement of orexin1 receptors. $\mathrm{Br} J$ Pharmacol 162:880-889.

King AC, de Wit H, McNamara PJ, Cao D (2011) Rewarding, stimulant, and sedative alcohol responses and relationship to future binge drinking. Arch Gen Psychiatry 68:389-399.

Kringelbach ML, Rolls ET (2004) The functional neuroanatomy of the human orbitofrontal cortex: evidence from neuroimaging and neuropsychology. Prog Neurobiol 72:341-372.

Lejuez CW, Magidson JF, Mitchell SH, Sinha R, Stevens MC, de Wit $H(2010)$ Behavioral and biological indicators of impulsivity in the development of alcohol use, problems, and disorders. Alcohol Clin Exp Res 34:1334-1345.

Li J, Cheng Y, Bian W, Liu X, Zhang C, Ye JH (2010) Region-specific induction of FosB/ $\Delta$ FosB by voluntary alcohol intake: effects of naltrexone. Alcohol Clin Exp Res 34:1742-1750.

London ED, Ernst M, Grant S, Bonson K, Weinstein A (2000) Orbitofrontal cortex and human drug abuse: functional imaging. Cereb Cortex 10:334-342.

Lopatina N, McDannald MA, Styer CV, Peterson JF, Sadacca BF, Cheer JF, Schoenbaum G (2016) Medial Orbitofrontal Neurons Preferentially Signal Cues Predicting Changes in Reward during Unblocking. The Journal of neuroscience: the official journal of the Society for Neuroscience 36:8416-8424.

Lucantonio F, Caprioli D, Schoenbaum G (2014) Transition from 'model-based' to 'model-free' behavioral control in addiction: involvement of the orbitofrontal cortex and dorsolateral striatum. Neuropharmacology 76:407-415.

Lukas SE, Lowen SB, Lindsey KP, Conn N, Tartarini W, Rodolico J, Mallya G, Palmer C, Penetar DM (2013) Extended-release naltrexone (XR-NTX) attenuates brain responses to alcohol cues in alcohol-dependent volunteers: a bold FMRI study. Neuroimage 78:176-185

Mainen ZF, Kepecs A (2009) Neural representation of behavioral outcomes in the orbitofrontal cortex. Curr Opin Neurobiol 19:84-91.

McDannald MA, Jones JL, Takahashi YK, Schoenbaum G (2014a) Learning theory: a driving force in understanding orbitofrontal function. Neurobiol Learn Mem 108:22-27.

McDannald MA, Esber GR, Wegener MA, Wied HM, Liu TL, Stalnaker TA, Jones JL, Trageser J, Schoenbaum G (2014b) Orbitofrontal neurons acquire responses to 'valueless' Pavlovian cues during unblocking. Elife 3:e02653.

McGuier NS, Padula AE, Lopez MF, Woodward JJ, Mulholland PJ (2015) Withdrawal from chronic intermittent alcohol exposure increases dendritic spine density in the lateral orbitofrontal cortex of mice. Alcohol 49:21-27.

Mitchell JM, O'Neil JP, Janabi M, Marks SM, Jagust WJ, Fields HL (2012) Alcohol consumption induces endogenous opioid release in the human orbitofrontal cortex and nucleus accumbens. Sci Transl Med 4:116ra6.

Momeni S, Roman E (2014) Subgroup-dependent effects of voluntary alcohol intake on behavioral profiles in outbred Wistar rats. Behav Brain Res 275:288-296.

Moorman DE (2018) The role of the orbitofrontal cortex in alcohol use, abuse, and dependence. Prog Neuropsychopharmacol Biol Psychiatry 87:85-107.

Moorman DE, Aston-Jones G (2009) Orexin-1 receptor antagonism decreases ethanol consumption and preference selectively in high-ethanol-preferring Sprague-Dawley rats. Alcohol 43:379386.

Moorman DE, Aston-Jones G (2014) Orbitofrontal cortical neurons encode expectation-driven initiation of reward-seeking. J Neurosci 34:10234-10246.

Moorman DE, Aston-Jones G (2015) Prefrontal neurons encode context-based response execution and inhibition in reward seeking and extinction. Proc Natl Acad Sci USA 112:9472-9477.

Moorman DE, James MH, Kilroy EA, Aston-Jones G (2016) Orexin/ hypocretin neuron activation is correlated with alcohol seeking and preference in a topographically specific manner. Eur $\mathrm{J}$ Neurosci 43:710-720.

Moorman DE, James MH, Kilroy EA, Aston-Jones G (2017) Orexin/ hypocretin-1 receptor antagonism reduces ethanol self-administration and reinstatement selectively in highly-motivated rats. Brain Res 1654:34-42.

Myrick H, Anton RF, Li X, Henderson S, Drobes D, Voronin K, George MS (2004) Differential brain activity in alcoholics and social drinkers to alcohol cues: relationship to craving. Neuropsychopharmacology 29:393-402.

Myrick H, Anton RF, Li X, Henderson S, Randall PK, Voronin K (2008) Effect of naltrexone and ondansetron on alcohol cue-induced activation of the ventral striatum in alcohol-dependent people. Arch Gen Psychiatry 65:466-475.

Nimitvilai S, Lopez MF, Mulholland PJ, Woodward JJ (2016) Chronic intermittent ethanol exposure enhances the excitability and synaptic plasticity of lateral orbitofrontal cortex neurons and induces a tolerance to the acute inhibitory actions of ethanol. Neuropsychopharmacol 41:1112-1127.

Nimitvilai S, Lopez MF, Mulholland PJ, Woodward JJ (2017a) Ethanol dependence abolishes monoamine and GIRK (Kir3) channel inhibition of orbitofrontal cortex excitability. Neuropsychopharmacology 42:1800-1812.

Nimitvilai S, Uys JD, Woodward JJ, Randall PK, Ball LE, Williams RW, Jones BC, Lu L, Grant KA, Mulholland PJ (2017b) Orbitofrontal neuroadaptations and cross-species synaptic biomarkers in heavy-drinking macaques. J Neurosci 37:3646-3660.

O'Doherty JP (2007) Lights, camembert, action! The role of human orbitofrontal cortex in encoding stimuli, rewards, and choices. Ann NY Acad Sci 1121:254-272.

Padoa-Schioppa C (2011) Neurobiology of economic choice: a good-based model. Annu Rev Neurosci 34:333-359.

Padoa-Schioppa C, Assad JA (2006) Neurons in the orbitofrontal cortex encode economic value. Nature 441:223-226.

Porrino LJ, Lyons D (2000) Orbital and medial prefrontal cortex and psychostimulant abuse: studies in animal models. Cereb Cortex 10:326-333.

Ray MH, Hanlon E, McDannald MA (2018) Lateral orbitofrontal cortex partitions mechanisms for fear regulation and alcohol consumption. PLoS One 13:e0198043.

Renteria R, Baltz ET, Gremel CM (2018) Chronic alcohol exposure disrupts top-down control over basal ganglia action selection to produce habits. Nat Commun 9:211.

Risinger RC, Salmeron BJ, Ross TJ, Amen SL, Sanfilipo M, Hoffmann RG, Bloom AS, Garavan H, Stein EA (2005) Neural correlates of high and craving during cocaine self-administration using BOLD fMRI. Neuroimage 26:1097-1108.

Roesch MR, Bryden DW, Cerri DH, Haney ZR, Schoenbaum G (2012) Willingness to wait and altered encoding of time-discounted 
reward in the orbitofrontal cortex with normal aging. $\mathrm{J}$ Neurosci 32:5525-5533.

Rolls ET (2015) Taste, olfactory, and food reward value processing in the brain. Prog Neurobiol 127-128:64-90.

Rudebeck PH, Murray EA (2014) The orbitofrontal oracle: cortical mechanisms for the prediction and evaluation of specific behavioral outcomes. Neuron 84:1143-1156.

Sadacca BF, Wied HM, Lopatina N, Saini GK, Nemirovsky D, Schoenbaum G (2018) Orbitofrontal neurons signal sensory associations underlying model-based inference in a sensory preconditioning task. Elife 7:e30373.

Schacht JP, Anton RF, Myrick H (2013a) Functional neuroimaging studies of alcohol cue reactivity: a quantitative meta-analysis and systematic review. Addict Biol 18:121-133.

Schacht JP, Anton RF, Voronin KE, Randall PK, Li X, Henderson S, Myrick H (2013b) Interacting effects of naltrexone and OPRM1 and DAT1 variation on the neural response to alcohol cues. Neuropsychopharmacology 38:414-422.

Schacht JP, Anton RF, Randall PK, Li X, Henderson S, Myrick H (2014) Varenicline effects on drinking, craving and neural reward processing among non-treatment-seeking alcohol-dependent individuals. Psychopharmacology (Berl) 231:3799-3807.

Schoenbaum G, Shaham Y (2008) The role of orbitofrontal cortex in drug addiction: a review of preclinical studies. Biol Psychiatry 63:256-262

Schoenbaum G, Roesch MR, Stalnaker TA, Takahashi YK (2009) A new perspective on the role of the orbitofrontal cortex in adaptive behaviour. Nat Rev Neurosci 10:885-892.

Schultz W (2010) Subjective neuronal coding of reward: temporal value discounting and risk. Eur J Neurosci 31:2124-2135.

Sharko AC, Kaigler KF, Fadel JR, Wilson MA (2013) Individual differences in voluntary ethanol consumption lead to differential activation of the central amygdala in rats: relationship to the anxiolytic and stimulant effects of low dose ethanol. Alcohol Clin Exp Res 37 [Suppl 1]:E172-E180.

Sharpe MJ, Schoenbaum G (2016) Back to basics: making predictions in the orbitofrontal-amygdala circuit. Neurobiol Learn Mem 131:201-206.
Simms JA, Steensland P, Medina B, Abernathy KE, Chandler LJ, Wise R, Bartlett SE (2008) Intermittent access to $20 \%$ ethanol induces high ethanol consumption in Long-Evans and Wistar rats. Alcohol Clin Exp Res 32:1816-1823.

Spoelder M, Hesseling P, Baars AM, Lozeman-van 't Klooster JG, Rotte MD, Vanderschuren LJ, Lesscher HM (2015) Individual variation in alcohol intake predicts reinforcement, motivation, and compulsive alcohol use in rats. Alcohol Clin Exp Res 39:2427-2437.

Stalnaker TA, Cooch NK, Schoenbaum G (2015) What the orbitofrontal cortex does not do. Nat Neurosci 18:620-627.

Takahashi YK, Chang CY, Lucantonio F, Haney RZ, Berg BA, Yau HJ, Bonci A, Schoenbaum G (2013) Neural estimates of imagined outcomes in the orbitofrontal cortex drive behavior and learning. Neuron 80:507-518.

Tremblay L, Schultz W (1999) Relative reward preference in primate orbitofrontal cortex. Nature 398:704-708.

Volkow ND, Fowler JS (2000) Addiction, a disease of compulsion and drive: involvement of the orbitofrontal cortex. Cereb Cortex 10:318-325.

Volkow ND, Wang GJ, Telang F, Fowler JS, Logan J, Jayne M, Ma Y, Pradhan K, Wong C (2007) Profound decreases in dopamine release in striatum in detoxified alcoholics: possible orbitofrontal involvement. J Neurosci 27:12700-12706.

Wallis JD (2011) Cross-species studies of orbitofrontal cortex and value-based decision-making. Nat Neurosci 15:13-19.

Walton ME, Behrens TE, Noonan MP, Rushworth MF (2011) Giving credit where credit is due: orbitofrontal cortex and valuation in an uncertain world. Ann NY Acad Sci 1239:14-24.

Whelan R, Conrod PJ, Poline JB, Lourdusamy A, Banaschewski T, Barker GJ, Bellgrove MA, Büchel C, Byrne M, Cummins TDR, Fauth-Bühler M, Flor H, Gallinat J, Heinz A, Ittermann B, Mann K, Martinot JL, Lalor EC, Lathrop M, Loth E, et al. (2012) Adolescent impulsivity phenotypes characterized by distinct brain networks. Nat Neurosci 15:920-925.

Winstanley CA (2007) The orbitofrontal cortex, impulsivity, and addiction: probing orbitofrontal dysfunction at the neural, neurochemical, and molecular level. Ann NY Acad Sci 1121:639-655.

Wise RA (1975) Maximization of ethanol intake in the rat. Adv Exp Med Biol 59:279-294 